Article

\title{
Ground-Based Measurements of the 2014-2015 Holuhraun Volcanic Cloud (Iceland)
}

Melissa A. Pfeffer 1,* (D), Baldur Bergsson ${ }^{1}$, Sara Barsotti ${ }^{1}$, Gerður Stefánsdóttir ${ }^{1}$, Bo Galle ${ }^{2}$, Santiago Arellano ${ }^{2}$, Vladimir Conde ${ }^{2}$, Amy Donovan ${ }^{3}$, Evgenia Ilyinskaya ${ }^{4}$, Mike Burton ${ }^{5}$, Alessandro Aiuppa ${ }^{6}$, Rachel C. W. Whitty ${ }^{4}$, Isla C. Simmons ${ }^{7}$, Pórður Arason ${ }^{1}$, Elín B. Jónasdóttir ${ }^{1}$, Nicole S. Keller ${ }^{8}$, Richard F. Yeo ${ }^{9}$, Hermann Arngrímsson ${ }^{1}$, Porsteinn Jóhannsson 8 (D), Mary K. Butwin 1,10, Robert A. Askew ${ }^{10}$ (D), Stéphanie Dumont 10,11, Sibylle von Löwis ${ }^{1}$, Porgils Ingvarsson ${ }^{1}$, Alessandro La Spina ${ }^{12}$, Helen Thomas ${ }^{13}$, Fred Prata ${ }^{14}$, Fausto Grassa ${ }^{15}$ (D), Gaetano Giudice ${ }^{15}$, Andri Stefánsson ${ }^{10}$, Frank Marzano ${ }^{16}$, Mario Montopoli ${ }^{17}$ and Luigi Mereu ${ }^{16}$

1 Icelandic Meteorological Office, Bústaðavegur 7-9, 108 Reykjavík, Iceland; bb@vedur.is (B.B.); sara@vedur.is (S.B.); gerdur@vedur.is (G.S.); arason@vedur.is (P.A.); elin@vedur.is (E.B.J.); hermann@vedur.is (H.A.); mkb5@hi.is (M.K.B.); sibylle@vedur.is (S.v.L.); thorgils@vedur.is (P.I.) Department of Space, Earth and Environment, Chalmers University of Technology, SE-412 96 Göteborg, Sweden; bo.galle@chalmers.se (B.G.); santiago.arellano@chalmers.se (S.A.);

vladimir.conde@chalmers.se (V.C.)

3 Department of Geography, King's College London, WC2R 2LS London, UK; amy.donovan@kcl.ac.uk

4 School of Earth and Environment, University of Leeds, LS2 9JT Leeds, UK; e.ilyinskaya@leeds.ac.uk (E.I.); eercww@leeds.ac.uk (R.C.W.W.)

5 School of Earth and Environmental Sciences, University of Manchester, M13 9P Manchester, UK; mike.burton@manchester.ac.uk

6 Dipartimento DiSTeM, University of Palermo, Via Archirafi 36, 90123 Palermo, Italy; alessandro.aiuppa@unipa.it

7 School of GeoSciences, University of Edinburgh, EH8 9XP Edinburgh, UK; isla.simmons@ed.ac.uk

8 Environment Agency of Iceland, Suðurlandsbraut 24, 108 Reykjavík, Iceland; nicole.keller@umhverfisstofnun.is (N.S.K.); thorsteinnj@umhverfisstofnun.is (P.J.)

9 AUV Consultants, 52Vesturás, Reykjavík 101, Iceland; richard@auvconsultants.com

10 Institute of Earth Sciences, University of Iceland, Sæmundargata 2, 101 Reykjavík, Iceland; raa22@hi.is (R.A.A.); ; sdumont@segal.ubi.pt (S.D.); as@hi.is (A.S.)

11 Instituto Dom Luiz, University of Beira Interior, Rua Marques d'Avila e Boloma, 6201-001 Covilhã, Portugal

12 Istituto Nazionale di Geofisica e Vulcanologia- Sezione di Catania, 95125 Catania, Italy; alessandro.laspina@ingv.it

13 School of Earth Sciences, University of Bristol, BS8 1TH Bristol, UK; helen.thomas@bristol.ac.uk

14 AIRES Pty Ltd, PO Box 156, Mt Eliza, Victoria 3930, Australia; fred_prata@hotmail.com

15 Istituto Nazionale di Geofisica e Vulcanologia- Sezione di Palermo, Via Ugo la Malfa 153, 90146 Palermo, Italy; fausto.grassa@ingv.it (F.G.); gaetano.giudice@ingv.it (G.G.)

16 Sapienza, University of Rome, 00184 Rome, Italy; marzano@diet.uniroma1.it (F.M.); mereu@diet.uniroma1.it (L.M.)

17 National Research Council of Italy, Institute of Atmospheric Sciences and Climate, Via Fosso del Cavaliere 100, 00133 Rome, Italy; m.montopoli@isac.cnr.it

* Correspondence: melissa@vedur.is; Tel.: +354-893-5157

Received: 13 November 2017; Accepted: 10 January 2018; Published: 18 January 2018

Abstract: The 2014-2015 Bárðarbunga fissure eruption at Holuhraun in central Iceland was distinguished by the high emission of gases, in total $9.6 \mathrm{Mt} \mathrm{SO}_{2}$, with almost no tephra. This work collates all ground-based measurements of this extraordinary eruption cloud made under particularly challenging conditions: remote location, optically dense cloud with high $\mathrm{SO}_{2}$ column amounts, low UV intensity, frequent clouds and precipitation, an extensive and hot lava field, developing ramparts, and high-latitude winter conditions. Semi-continuous measurements of $\mathrm{SO}_{2}$ flux with 
three scanning DOAS instruments were augmented by car traverses along the ring-road and along the lava. The ratios of other gases $/ \mathrm{SO}_{2}$ were measured by OP-FTIR, MultiGAS, and filter packs. Ratios of $\mathrm{SO}_{2} / \mathrm{HCl}=30-110$ and $\mathrm{SO}_{2} / \mathrm{HF}=30-130$ show a halogen-poor eruption cloud. Scientists on-site reported extremely minor tephra production during the eruption. OPC and filter packs showed low particle concentrations similar to non-eruption cloud conditions. Three weather radars detected a droplet-rich eruption cloud. Top of eruption cloud heights of $0.3-5.5 \mathrm{~km}$ agl were measured with ground- and aircraft-based visual observations, web camera and NicAIR II infrared images, triangulation of scanning DOAS instruments, and the location of $\mathrm{SO}_{2}$ peaks measured by DOAS traverses. Cloud height and emission rate measurements were critical for initializing gas dispersal simulations for hazard forecasting.

Keywords: Holuhraun; Bárðarbunga; gas; $\mathrm{SO}_{2}$; cloud height; eruption monitoring; fissure eruption

\section{Introduction}

The 2014-2015 fissure eruption of Bárðarbunga (also known as Veiðivötn) lasted six months, from 31 August 2014-27 February 2015. This was the largest Icelandic eruption in over 200 years: $1.6 \pm 0.3 \mathrm{~km}^{3}$ of lava and prodigious amounts of gases were released [1]. The Bárðarbunga volcanic system includes a central volcano capped by the Vatnajökull glacier in the highlands of central Iceland, and also includes a $190 \mathrm{~km}$ long fissure swarm extending to the northeast and southwest from the central volcano. Bárðarbunga erupts frequently, with an average of two eruptions per century over the last 11 centuries [2]. The greatest amount of lava known to have been produced during a Bárðarbunga eruption is $>20 \mathrm{~km}^{3}$, so while the 2014-2015 eruption was extraordinary in recent times, it is well within the known behavior of this volcanic system.

The eruption was preceded by seven years of increased seismicity within the volcanic system, which escalated for two months, followed by two weeks of migration of seismic swarms and associated ground deformation manifesting as a rifting event, finally culminating in a small, few-hours long lava effusion on 29 August. Two days later, on 31 August, the six-month long Holuhraun eruption started. The geophysical changes were closely monitored in real-time as potential precursors to an eruption. A segmented dyke intrusion originated at the Bárðarbunga central volcano that propagated laterally over $45 \mathrm{~km}$. This intrusion culminated in an effusive fissure eruption at the end of the dyke [3], a few $\mathrm{km}$ north of the Vatnajökull glacier, where a lava field of the same name, Holuhraun, had erupted previously in 1862-1864, also originating from Bárðarbunga [4].

This eruption was one of the most polluting volcanic eruptions in centuries. The remote location and winter-season timing of the eruption, however, reduced its potential impact on people and the environment in Iceland [1]. The prodigious emissions of gases and the sulfate aerosol formed as the eruption cloud aged impacted the air quality in populated areas of Iceland significantly throughout the course of the eruption [5]. The remote location, however, meant that the concentrations of gases were diluted before reaching population centers. The dry atmosphere and weak winter sunlight conditions during most of the eruption slowed down the formation of sulfate aerosol, which, despite these dampening effects, exceeded Icelandic health standards far above legal limits [1,5]. If the dyke had breached the surface beneath the glacier as opposed to north of it, ash and floods would likely have been produced [6].

The anticipatory period allowed for the continued development of gas and particle monitoring instrumentation and techniques suitable for Icelandic conditions, benefiting from the EU-FP7 FUTUREVOLC project. This project fostered instrumentation development, deployment strategies, data processing techniques, and strengthened relationships between Icelandic and foreign collaborators for a better response during volcanic eruptions, and therefore contributed to the success of the eruption cloud monitoring. 
The eruption occurred in a remote, very difficult to access location, so in spite of the instrumental improvements made prior to the eruption, there were serious challenges for acquiring data and maintaining the instruments. The nearest farm and municipality are each about $100 \mathrm{~km}$ away. The eruption site is located within Dyngjusandur, the most extensive dust source area in Iceland [7], an active sandy desert where dust storms are very common. Tremendous efforts were made to install continuous monitoring instrumentation; however, because of these harsh field conditions, there are many temporal gaps in the data. Field campaigns for non-continuous instrumentation overcame many difficulties, mainly pertaining to weather and the high concentration of gas near the eruption vent. Traveling to the field and maintaining instrumentation was a major undertaking during winter conditions.

The aim of this paper is to bring together all of the ground-based measurements of the volcanic cloud. We report on the results and discuss what the combined data sets tell us about this extraordinary event and how to optimize the monitoring of volcanic clouds from future fissure eruptions in Iceland and elsewhere.

\section{Materials and Methods}

\subsection{DOAS}

The primary monitoring tool for this long-lasting, gas-rich volcanic cloud was Differential Optical Absorption Spectrometry (DOAS) [8]. Ultraviolet light from the sun, scattered from aerosols and molecules in the atmosphere, is collected by a telescope. Light is transferred from the telescope to the grating spectrometer by a quartz optical fiber. In-cloud spectra are analyzed against clear-sky and dark spectra and the differential slant column of various gases, primarily $\mathrm{SO}_{2}$, is derived.

\subsubsection{ScanDOAS}

Through the support of the FUTUREVOLC project, a version of the NOVAC ScanDOAS instrument $[9,10]$ was developed that is adapted to high latitudes with low UV radiation and severe meteorological conditions. Two major developments were made: the standard Ocean Optics SD2000 spectrometer was replaced by the more UV-sensitive Ocean Optics Maya2000 Pro spectrometer, and the scanning device was modified to avoid external moving parts to make it more robust in freezing conditions (Figure 1). The scanning device was modified by replacing the rotating hood with a quartz window with a closed scanner with a cylindrical quartz tube, and a cylindrical lens was included in the optical system. This changed the field of view (FOV) of the instrument to be rectangular instead of circular, covering the full $7.2^{\circ}$ angle used as the scan interval. A fixed exposure time of $200 \mathrm{~ms}$ was used. Co-adding 15 spectra resulted in a total time of $2 \mathrm{~min}$ for one scan to be completed.

At the onset of the fissure eruption at Holuhraun, a ScanDOAS instrument, DOAS 25, was prepared at the Icelandic Meteorological Office (IMO) and installed at the eruption site on the second day of the eruption (Figure 2). In the first week of September, a second ScanDOAS instrument, DOAS 27, was installed, which was made available through cooperation with Prof. Konradin Weber at Fachhochschule Düsseldorf. Data transfer and real-time evaluation was fully implemented at IMO within the first couple of days of the eruption. After about two weeks, DOAS 27 was surrounded by active lava flows and eventually stopped transmitting data in the absence of sufficient power. During and after the remaining six months of the eruption, one or two ScanDOAS instruments, DOAS 25 and DOAS 26, were operational. DOAS 26 was moved around the eruption site in response to the advancement of the lava. Its final location is shown in Figure 2. 


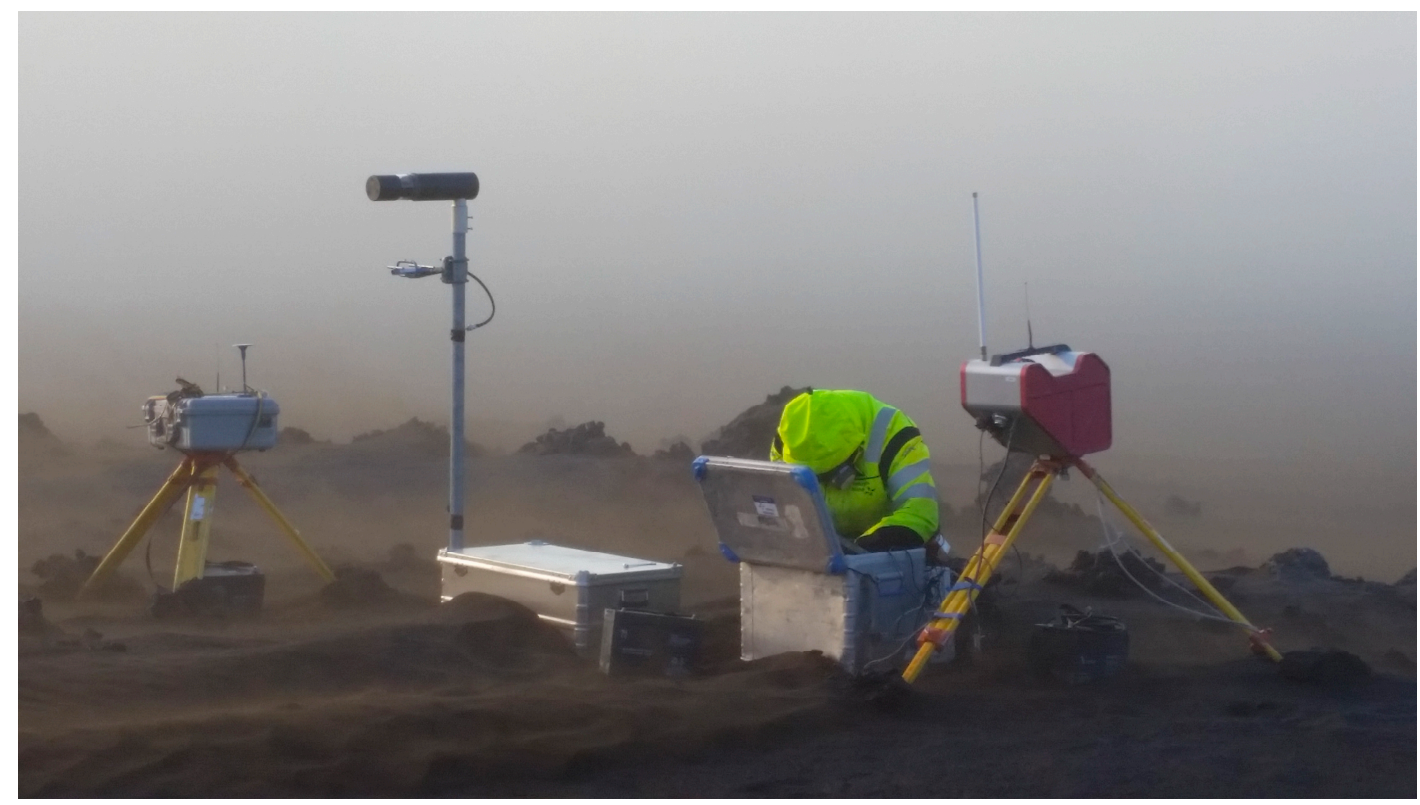

Figure 1. OPC, ScanDOAS, and NicAIR II at Porvaldshraun, $10 \mathrm{~km}$ northeast of the main eruption vent. The OPC and NicAIR II were moved from this site to their final locations (Möðrudalur and Vaðalda, respectively) due to problems operating them at this site. The visibility is poor because of a dust storm, which are common here.

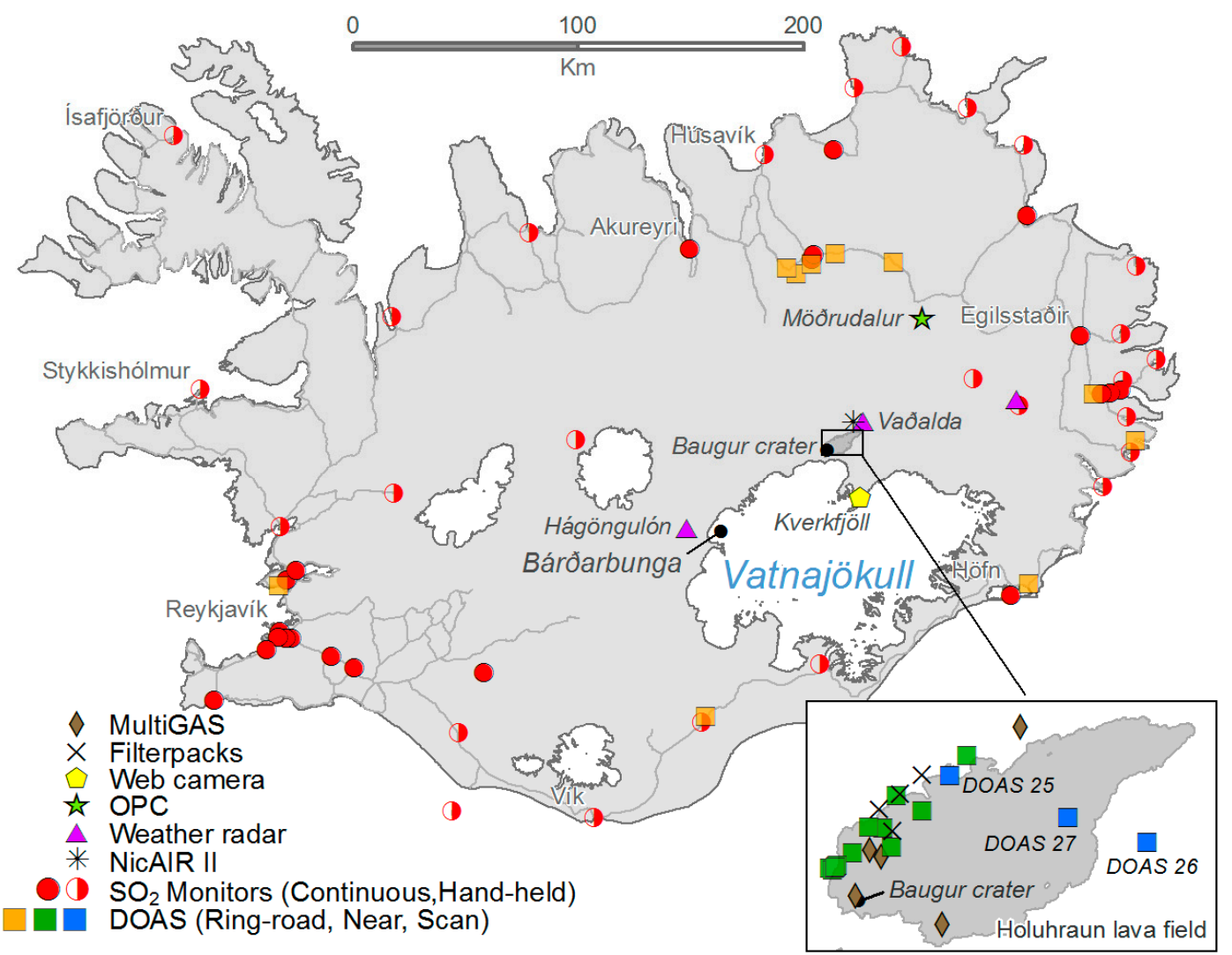

Figure 2. Map of Iceland showing the locations of the ground-based volcanic cloud monitoring instruments. An inset of the area around the eruption site is enlarged. The DOAS instruments are identified by number as described in the main text of this section. The ring-road DOAS traverses are marked at the location with the maximum $\mathrm{SO}_{2}$ column amount. The near DOAS traverses are marked at the midpoint of the traverse. 
To calculate emission rates from the ScanDOAS data, wind speed, wind direction, and cloud height must be known. Wind direction and wind speed at the eruption cloud height were obtained from the HARMONIE numerical weather prediction model utilized by IMO [11]. HARMONIE runs on a regional scale over Iceland with a horizontal resolution of $2.5 \mathrm{~km}$ and an hourly forecast provided every six hours. Atmospheric parameters calculated by the model at an altitude of $850 \mathrm{hPa}$ (the model level closest to $1387 \mathrm{~m}$ elevation, explanation below) were used as representative of the conditions at the eruption cloud height for processing the ScanDOAS data.

When two ScanDOAS instruments simultaneously measured the eruption cloud, cloud height was derived by triangulation. After about two weeks, the second ScanDOAS instrument was trapped by an active lava flow and alternative methods were necessary to determine the cloud height. Direct observations from the field, observations from air craft, and web cam images were used during the eruption to estimate cloud heights. These showed a high temporal variance and disagreement between techniques. As a result, the average cloud height of $1387 \mathrm{~m}$ measured while the two ScanDOAS instruments were both operating, which is within the $1-3 \mathrm{~km}$ frequently reported by the various other cloud height observation methods listed above, was used for the processing of the DOAS data for the duration of the eruption.

Because of the extremely high emissions of $\mathrm{SO}_{2}$ from the fissure eruption at Holuhraun, in combination with severe atmospheric scattering [12], it was not possible to apply standard evaluation procedures for processing the ScanDOAS data. The spectral evaluation window was changed to 319-325 nm, where the absorption by $\mathrm{SO}_{2}$ is weaker, light intensity is stronger, and atmospheric scattering reduced, compared with the usual 310-325 nm interval. This did not remove all the effects of atmospheric scattering, so further data filtering was required to select data least affected by scattering.

Figure 3 analyzes the bias in $\mathrm{SO}_{2}$ flux caused by wind direction and wind speed based on all data collected during the eruption by DOAS 25. Wind direction produced the strongest bias in the data (Figure 3a). The greater the angle of the wind from line-of-sight from the main vent to the DOAS, the greater the amount of intervening atmosphere is included between the eruption cloud and the instrument, and the biggest impact from the so-called dilution of the absorption signal from scattering was found. This bias was removed by restricting the acceptable wind direction to $+/-15^{\circ}$ from the line-of-sight from the main vent to the instrument and filtering out data collected at other wind directions (Figure 3b). Work is on-going to develop an algorithm for the spectral data to make a first order compensation for the scattering effect of clean atmosphere outside of the eruption cloud [9], which could, in the future, make this filtering of the data for non-optimal wind directions unnecessary. Sensitivity analysis of the error in flux related to the scanning geometry shows that for conical scanning, uncertainties in wind direction of up to $40 \%$ produce errors in flux $<5 \%$, not considering scattering effects [13]. Figure $3 c$ shows the bias from wind speed. At low wind speeds, $<7.5 \mathrm{~m} / \mathrm{s}$, calculated fluxes increase as the wind speed increases. Restricting the wind speed to $\geq 7.5 \mathrm{~m} / \mathrm{s}$ removes this bias (Figure 3d). Days with fewer than three acceptable scans at an individual ScanDOAS were removed.

The ScanDOAS data was further used to detect $\mathrm{SO}_{2}$ emitted by the cooling lava field, as distinct from the emissions from the main vent. $\mathrm{SO}_{2}$ emissions from a lava field will typically form a broadly dispersed low-level haze [14]. The optical path through a uniform haze, and hence the $\mathrm{SO}_{2} \mathrm{column}$ density, will be greater at low elevation angles compared with high elevation angles with a shorter path through the haze. The distribution of column densities of $\mathrm{SO}_{2}$ in all DOAS scans collected during and after the eruption were visually inspected to identify the characteristic symmetrical trough-shape anticipated for a measurement through a uniform haze. Only scans with sufficient symmetry to indicate the presence of a uniform haze were used to calculate the $\mathrm{SO}_{2}$ flux from the lava field. These data were filtered for wind direction $\left( \pm 20^{\circ}\right.$ from line-of-sight from the lava field to the instrument), and the $\mathrm{SO}_{2}$ flux was calculated assuming the width of the haze was equal to the width of the lava field as viewed from the ScanDOAS instrument. The uncertainty of these measurements is estimated to be $45 \%$. The daily average value of $\mathrm{SO}_{2}$ flux from the lava field was assessed for the months following the end of the eruption. The lava field emission rate data has been previously published in [14]. 

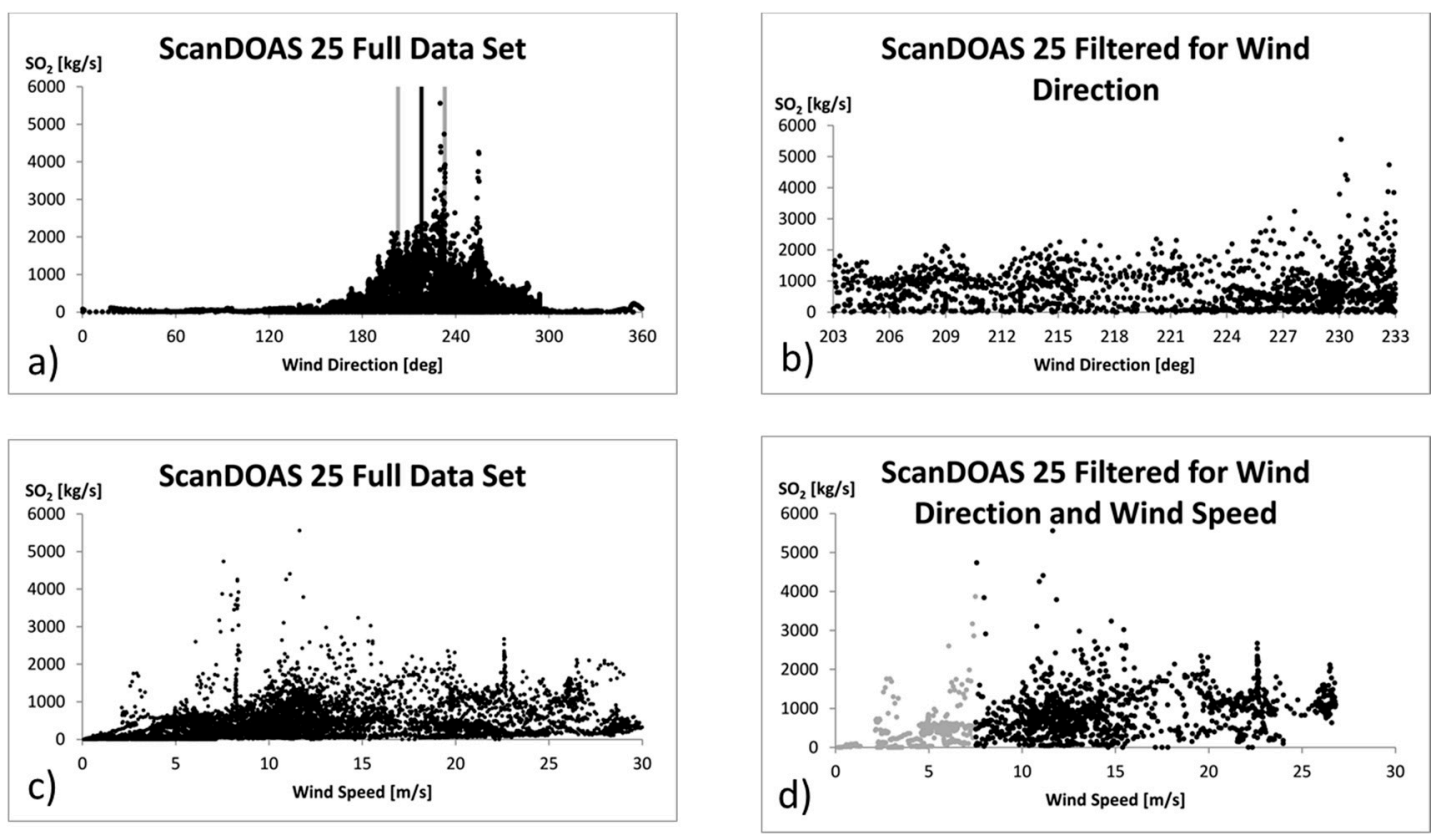

Figure 3. (a) Impact of wind direction on $\mathrm{SO}_{2}$ flux. The vertical black line shows the direct line of sight from the main eruption vent to the instrument. The vertical gray lines show the direct line of sight $\pm 15^{\circ}$; (b) $\mathrm{SO}_{2}$ flux filtered for wind direction; (c) Impact of wind speed on $\mathrm{SO}_{2}$ flux; (d) $\mathrm{SO}_{2}$ flux filtered for wind direction and wind speed. The measurements in gray were made at weak wind speeds and have been filtered out.

\subsubsection{Down-Wind MobileDOAS and In Situ $\mathrm{SO}_{2}$ Traverses}

Iceland is encircled by the so-called ring-road highway (Figure 2). Traverses of aged, diluted, down-wind eruption clouds were made by mounting a MobileDOAS system on a car that drove along the ring-road of Iceland with the intention of transecting the transportation path of the eruption cloud. The MobileDOAS instrument is described in [15]. The location and time of the traversing instrument was obtained from a GPS, from which the integration of the cloud cross section column densities and cloud transport direction could be determined. A Thermo Scientific in situ $\mathrm{SO}_{2}$ analyzer was also transported by car during some of the traverses. The closest the ring-road comes to the eruption site is just over $100 \mathrm{~km}$, where the approximate age of the volcanic cloud would be $2.8 \mathrm{~h}$ at a $10 \mathrm{~m} / \mathrm{s}$ wind speed. This distance meant that the gases were diluted and therefore the DOAS spectra were not saturated as they sometimes were near-vent, and the ring-road is outside of the dust-producing region close to the eruption site, providing for easier, more immediate data processing. Aged clouds, however, may have lost $\mathrm{SO}_{2}$ due to gas-to-particle conversion and deposition. Successful MobileDOAS traverses were made during the eruption on seven days when the winds were conducive to producing a coherent eruption cloud and it was not raining or snowing. After a traverse was completed, the spectra were analyzed using the MobileDOAS software developed at Chalmers University of Technology, following standard DOAS procedures $[15,16]$ and the slant column of $\mathrm{SO}_{2}$ was derived. The ring-road traverses, a subset of the full DOAS data collected during the eruption, have been published previously in [1].

Near-lava field traverses were made on five days by mounting a DOAS on a car like for the ring-road traverses. The Thermo Scientific in situ $\mathrm{SO}_{2}$ analyzer is a rather large and delicate instrument that was never taken off of the main highways to the eruption site. The eruption cloud was rarely grounded near to the eruption site, as the large temperature gradient between the lava field and the ambient air encouraged the eruption cloud to remain aloft near-source. The near-field traverses were retrieved at 360-390 $\mathrm{nm}$ rather than the 319-325 $\mathrm{nm}$ used for the ScanDOAS retrievals. They were 
retrieved using DOASIS software and scripts available from [17]. A near-lava field scan was made on 21 January 2015 using the Avoscan system to drive the spectrometer [18].

The emission rate of $\mathrm{SO}_{2}$ was successfully measured by DOAS on 33 days during the 181 days of the eruption. The ScanDOAS installations, ring-road MobileDOAS traverses, and near-source traverses measured the flux on 23, seven, and five days, respectively. On the two days when $\mathrm{SO}_{2}$ flux was measured by more than one DOAS method, all flux measurements were averaged.

The uncertainty in the $\mathrm{SO}_{2}$ flux measurement by the ScanDOAS method has been given to be $54 \%$ for "fair" conditions, meaning situations where spectroscopic errors, atmospheric scattering, uncertainties in wind, and measurement geometry are not ideal, but it is not raining or snowing and the cloud is not strongly meandering [10]. This estimation pertains to measurements with the standard instrument deployed in the NOVAC network. For the instruments used in this work, the spectroscopic error (including spectrometer noise, errors in reference cross sections, changes of instrument line-shape, and fitting errors) is considered to be similar to the standard one and less than $15 \%$. While the signal to noise of a Maya2000 Pro is better than for a SD2000 spectrometer, the temperature sensitivity is larger. The measurement geometry error is kept low (estimated to be less than $10 \%$ ) in our measurements since the data is carefully selected to minimize sampling errors. The cloud speed error is unknown, but good correspondence between forecasted and observed gas transport suggests that this uncertainty may be less than $15 \%$. The cloud height error can be considered to be less than $20 \%$. The most important source of uncertainty is the effect from atmospheric scattering. UV DOAS measurements of an optically thick cloud surrounded by a hazy environment are affected by dilution of the absorption signal caused by scattering of light before it reaches the cloud, leading to an underestimation of the flux, and by multiple-scattering within the cloud, leading to an overestimation of the flux [19]. In addition to these complexities, strong absorption by $\mathrm{SO}_{2}$ causes a suppression of large optical paths, resulting in an underestimation of the flux. The bias from wind direction (Figure 3) suggests that the scattering effect of dilution of the absorption signal prior to reaching the cloud was significant and probably the dominant source of uncertainty for our measurements. This follows from the environment where the eruption took place being so dusty. The data filtering removes the ScanDOAS measurements most affected by atmospheric scattering. From analysis of the ring-road traverse measurements [9], an underestimation due to dilution of up to $40 \%$ was found in the distant cloud. For the near-vent measurements, the distance to the cloud was shorter, but the atmosphere was hazier and the cloud was more concentrated. We think these effects together result in a net underestimation of the flux that increases with increasing distance from the cloud and attribute a value of at least $-40 \%$ to $+10 \%$. The total flux uncertainty in our scanning and near and far traverse DOAS measurements is estimated to be $-50 \%$ to $+30 \%$.

\subsection{Icelandic Environmental Agency Network}

Prior to the eruption, air quality in Iceland was monitored in real-time by a network of 11 automatic stations operated by the Environment Agency of Iceland (EAI) [1,5]. The network measured the ground-level concentration of $\mathrm{SO}_{2}, \mathrm{H}_{2} \mathrm{~S}, \mathrm{NO}, \mathrm{NO}_{2}$, and particulate matter $\left(\mathrm{PM}_{10}\right.$ and $\left.\mathrm{PM}_{2.5}\right)$, located in areas exposed to pollution from anthropogenic sources including factories and aluminum smelters. The number of $\mathrm{SO}_{2}$-monitoring stations was increased as the eruption progressed and 21 stations were operating at the end of the eruption. These were installed in communities around the country to monitor populated areas. The data were streamed in real-time to EAI and the data was made publicly-available on their web-site and at IMO.

In addition to this permanent network, hand-held personal sensors were distributed to local police. These were set up to activate an acoustic alarm if gas concentration thresholds were exceeded.

Measurements from the automatic stations and hand-held sensors, in conjunction with $\mathrm{SO}_{2}$ ground-level concentration forecasts generated by IMO, were used by Icelandic Civil Protection and Emergency Management (NCIP DCP) to warn the public about unhealthy concentrations of gases and to advise them to stay indoors when high concentrations of $\mathrm{SO}_{2}$ were detected or forecasted. 
Monitoring data from the automatic stations were used for validating the $\mathrm{SO}_{2}$ dispersal forecasts provided by IMO using the CALPUFF model [1].

\subsection{Open-Path Fourier Transform IR}

An open-path Fourier transform (OP-FTIR) spectrometer (MIDAC model M4401-S-E) was used successfully on seven days during the eruption. The OP-FTIR has been used intensively in Italy for monitoring gas emissions from Stromboli [20,21] and Etna [22], both between and during eruptions. Successful measurements have been made previously in Iceland during the 2010 eruption of Fimmvörðuháls [23] and the 2010 Eyjafjallajökull summit eruption [24]. During Holuhraun, gas compositions were measured with OP-FTIR by pointing the instrument directly towards the volcanic plume (vertically rising part of the volcanic cloud) or cloud with either lava or the sun as the IR source. The OP-FTIR spectra were analyzed using a forward model and non-linear fitting algorithm [21] after collecting the data. Each spectrum records the slant column amounts of gases contained in the atmosphere, in the volcanic cloud, or both. For example, $\mathrm{H}_{2} \mathrm{O}$ vapor, typically the most abundant magmatic gas, is also abundant in the atmosphere, as is $\mathrm{CO}_{2}$, while magmatic species such as $\mathrm{SO}_{2}, \mathrm{HCl}$, and HF only exist in trace amounts in the non-eruption atmosphere. The ratios of the column densities are equal to the molar ratio of the measured gases. A subset of the FTIR data has been previously published in [23], and model calculations based on a subset of the data have been previously published in [25].

\subsection{MultiGAS}

The Multi-component Gas Analysis system (MultiGAS) instrument was developed by the University of Palermo and INGV-Palermo and modified for use in Iceland [26-28]. It measures in situ (at $0.1 \mathrm{~Hz}$ rate) the concentrations of major volcanic gas species $\left(\mathrm{H}_{2} \mathrm{O}, \mathrm{CO}_{2}, \mathrm{SO}_{2}, \mathrm{H}_{2} \mathrm{~S}\right.$ ) in the atmosphere, by integrating (i) an infrared spectrometer for $\mathrm{CO}_{2}$ (Gascard II, calibration range 0-10,000 ppmv (0-1\%); accuracy $\pm 2 \%$, resolution, 3 ppmv); (ii) two specific electrochemical sensors for the measurement of $\mathrm{SO}_{2}$ (CityTechnology, sensor type 3ST/F, calibration range, 0-50 ppmv, accuracy, $\pm 5 \%$, resolution, $0.1 \mathrm{ppmv}$ ) and $\mathrm{H}_{2} \mathrm{~S}$ (CityTechnology, sensor type $2 \mathrm{E}$, calibration range, $0-50 \mathrm{ppmv}$, accuracy, $\pm 5 \%$, resolution, $0.1 \mathrm{ppmv}$ ); and (iii) temperature, pressure, and relative humidity (Galltec sensor, measuring range, $0-100 \% \mathrm{Rh}$, accuracy, $\pm 2 \%$ ) sensors for the calculation of $\mathrm{H}_{2} \mathrm{O}$ concentrations. Gas ratios measured with the MultiGAS are calculated using the Ratiocalc software [29]. The collected data are de-trended to adjust the baselines to zero to correct for instrument drift (largely due to increasing temperature in the instrument as it operates), and then ratios between species are calculated. Acceptable ratios were measured for at least five minutes when the gas concentration was at least $0.8 \mathrm{ppm}$ and have an $\mathrm{R}^{2}$ value greater than 0.5.

During the Holuhraun eruption, one MultiGAS measurement was made inside the active crater on the day between the first minor lava effusion and the main eruption (Figure 2). Measurements were made on the edge of the advancing lava field on four days during the eruption. In January 2015, a continuous monitoring MultiGAS was installed at Porvaldshraun, $10 \mathrm{~km}$ from the main eruption vent, and measurements were obtained of the aged, dilute cloud on eight days until the end of the eruption. A subset of this data has been previously published in [1] and model calculations based on a subset of the MultiGAS data have been previously published in [25].

\subsection{Filter Pack}

Filter pack samples to collect acidic gases, primarily $\mathrm{SO}_{2}, \mathrm{HF}$, and $\mathrm{HCl}$, in the near-source eruption cloud were collected on four days during the eruption (Figure 2). Three days were previously published in [30] and one day was previously published in [5]. Filter pack samples have also been reported in [31], independent from the official monitoring of the eruption. All samples were drawn through the filter pack apparatus by a pump and acidic gases were collected on base-impregnated Whatman filters. All samples were leached in deionized water in a laboratory and the solutions were analyzed 
for anion concentration using ion chromatography. All samples were blank corrected by treating filters in the same way as for samples followed by chemical analysis. The measurements included here are those where the F measured on the base-impregnated filter was $\geq 5 \mu \mathrm{g} / \mathrm{m}^{3}$; two previously-published samples are excluded due to the too low concentration of $\mathrm{F}$ collected. The filter pack samples collected by [5] also included a PM filter (Millipore, $47 \mathrm{~mm}$, AAWP, pore size $0.8 \mu \mathrm{m}$ ) in series before the gas filters. The mass of the PM was calculated by extracting elements from the PM using sequential leaching. The sum of the mass of all analyzed elements is calculated to represent the mass of the PM.

\section{6. $O P C$}

An Optical Particle Counter/Sizer (OPC/OPS) (OPS 3330, TSI Inc.) was installed at Möðrudalur, $72 \mathrm{~km}$ from the main eruption vent, from October 2014 until after the end of the eruption (Figure 2). Particle counts in 16 size bins from 0.3 to $10 \mu \mathrm{m}$ provided a sum every five minutes, and can be used to provide different temporal means or maxima. The OPC was deployed to monitor the concentration and size distribution of any ash or other particulate matter produced by the eruption, with the maximum detectable particles being $10 \mathrm{~m}$, so coarser ash would not be measured by this instrument.

A research campaign, independent from the official monitoring of the eruption, launched a balloon $9 \mathrm{~km}$ from the main crater to fly through the Holuhraun eruption cloud carrying a Light Optical Aerosol Counter (LOAC) [32].

\subsection{Weather Radar}

One permanent C-band radar at Fljótsdalsheiði ( $86 \mathrm{~km}$ from the eruption site), close to the city of Egilsstaðir, operated throughout the eruption (Figure 2). Two mobile X-band radars were moved close to their eruption targets within the first week of the eruption. One X-band radar was located in Vaðalda with a clear view of the eruptive fissure (20 km distance) and the other one was located in Hágöngulón, ready to detect an eruption cloud originating from the central Bárðarbunga volcano (36 km distance). There were persistent technical issues involved with operating the mobile radars in the highlands, including frequent radio communication disruptions, fuel consumption, sand storms harming the generators, and cooling and overheating problems. The C-band radar, part of the continuous weather monitoring of Iceland, operated throughout the entire eruption.

\subsection{Web Cam}

A web camera located in Kverkfjöll (Figure 2), about $25 \mathrm{~km}$ south of the main eruption vent, provided images every $10 \mathrm{~min}$. The camera image area was scaled using seven mountains visible on the images with elevations from 741-1682 $\mathrm{m}$ asl. The eruption cloud top seen in the images was transformed to the height profile above sea level vs. distance along the cloud assuming no lens distortion and that the cloud was transported in the direction $80^{\circ}$ east. The eruption cloud was detectable by this camera during the first $19 \mathrm{~km}$ from the eruption site. The maximum eruption cloud height often was detected a couple of kilometers down-wind from the eruption site. A subset of this data has been previously published in [33].

\subsection{NicAIR II}

A NicAIR II multi spectral infrared imaging camera was installed at Vaðalda, approximately $20 \mathrm{~km}$ from the main eruption vent, from 20 November 2014 until the end of the eruption (Figure 2). Gases and particles emit and absorb thermal radiation, which is detected by a microbolometer array fitted in the NicAIR infrared camera [34,35]. Radiation counts are then converted to radiance, and then to brightness temperatures (Kelvin) through a pre-determined instrument calibration scheme [34]. The NicAIR II camera operates in the 8-13 $\mu \mathrm{m}$ region of the infrared spectrum. A filter wheel contains one broadband $(8-13 \mu \mathrm{m})$ and three narrow band filters centered at $8.62 \mu \mathrm{m}, 10.0 \mu \mathrm{m}$, and $10.87 \mu \mathrm{m}$, selected to be sensitive to specific signatures in the cloud. Approximately one composite data image was recorded per minute due to the number of filters in use. The 8.62 and $10.87 \mu \mathrm{m}$ channels were 
processed to retrieve $\mathrm{SO}_{2}$ and the $10.0 \mu \mathrm{m}$ channel was used to determine the cloud temperature [35]. Similar instruments have been used previously on eruption clouds at Karymsky and Stromboli volcanoes to monitor $\mathrm{SO}_{2}$ and ash [36,37]. Good quality data was obtained on seven days in November and December 2014, as other days were hindered due to hardware problems and meteorological challenges (e.g., clouds obscuring the view, icing on the camera window).

Brightness temperature data were post-processed into $\mathrm{SO}_{2}$-sensitive images, including static and dynamic parameters. Dynamic parameters were assessed at least every $10 \mathrm{~min}$. The cloud temperature was obtained from the $10.0 \mu \mathrm{m}$ wavelength image, extracted using Fits Liberator software in an opaque section of the cloud. The ground level of the image was identified and all horizontal rows of data below this level were set to $\mathrm{SO}_{2}=$ null to remove noise and interference coming from the lava field with its high brightness temperatures. Background infrared radiation levels were determined by taking vertical profiles where the sky was clear, i.e., there was no coverage of the sky by the volcanic cloud or meteorological clouds. Whenever there was no suitable clear section, if low-lying background clouds were responsible, the horizontal rows including the low-lying clouds were set to $\mathrm{SO}_{2}=$ null, allowing processing of the image, otherwise the image was excluded. Parameters which remained constant include the distance from the camera to the main eruption vent and the angle of the camera above the horizontal. These two static parameters were used to calculate the dimensions of the NicAIR field of view (FOV).

Both cloud height and $\mathrm{SO}_{2}$ amount were calculated from the good quality images; however, the $\mathrm{SO}_{2}$ retrieval was severely impacted by the high concentrations of $\mathrm{H}_{2} \mathrm{O}$ in the eruption cloud. This caused the region closest to the eruption vent, where $\mathrm{SO}_{2}$ concentrations are expected to be greatest, to be opaque. $\mathrm{SO}_{2}$ retrievals were therefore significant underestimations and are not reported here, but can be found in [38]. Cloud heights were calculated following a revised methodology from [39] and [40]. The $10.0 \mu \mathrm{m}$ channel data was processed with pixel heights as defined by the camera geometry and distance from the camera to eruption vent. The apparent cloud top height in each image was then identified by the thermal contrast at the cloud's leading edge (Figure 4). Only data where the thermal contrast of the cloud's leading edge was clearly visible were used to estimate the apparent cloud heights. The recorded apparent cloud top height was taken at the edge of the FOV, at which point the cloud was furthest from the vent and at the maximum height recorded by the NicAIR camera. Due to large variations in cloud heights, an average hourly apparent cloud height was calculated for each hour of suitable data.

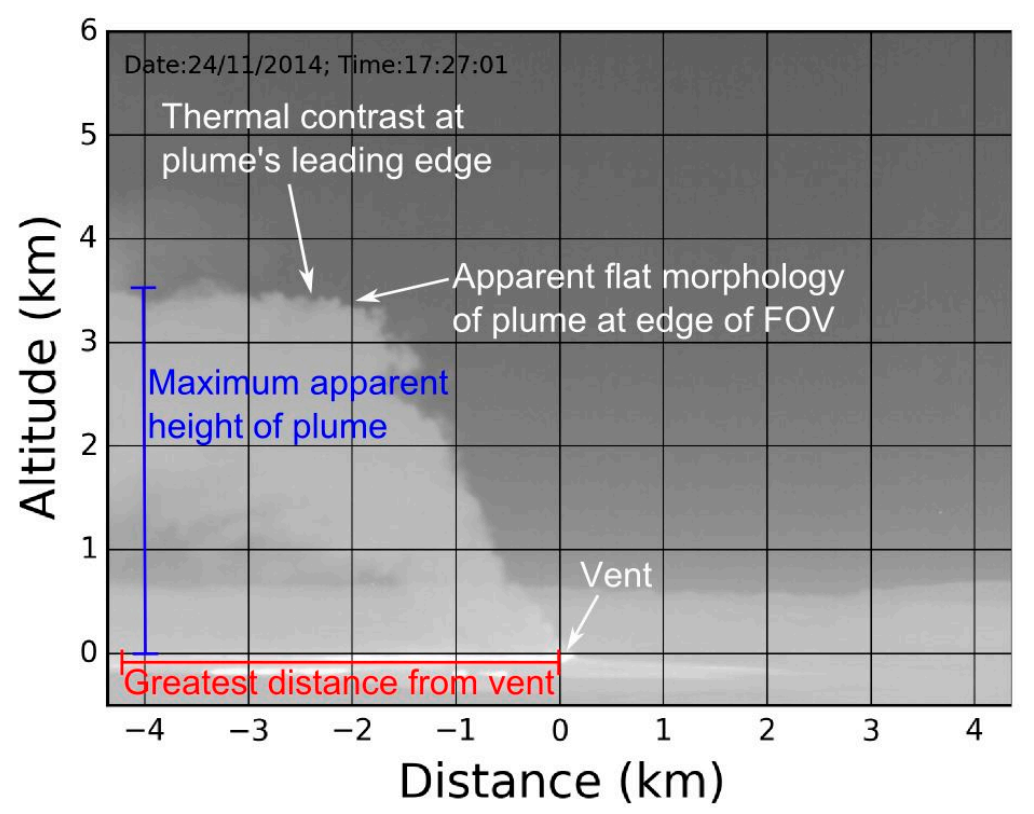

Figure 4. Apparent cloud top height measured from NicAIR II $10 \mu \mathrm{m}$ images. 
The apparent cloud height derived from the NicAIR image is not equivalent to the actual cloud top altitude. Due to the viewing geometry, the actual top of the cloud was hidden from the camera's view and the apparent cloud top often appeared flat in morphology as a result of this (Figure 5). In addition, wind transports the cloud away from the eruption vent and the altitude scale at the vent is not equivalent to the altitude scale at the cloud's location of maximum height. In order to calculate the actual altitude of the cloud top, the location of the cloud in relation to the camera was required so that a new altitude scale derived from the camera geometry and the distance between the camera and the cloud location could be calculated.

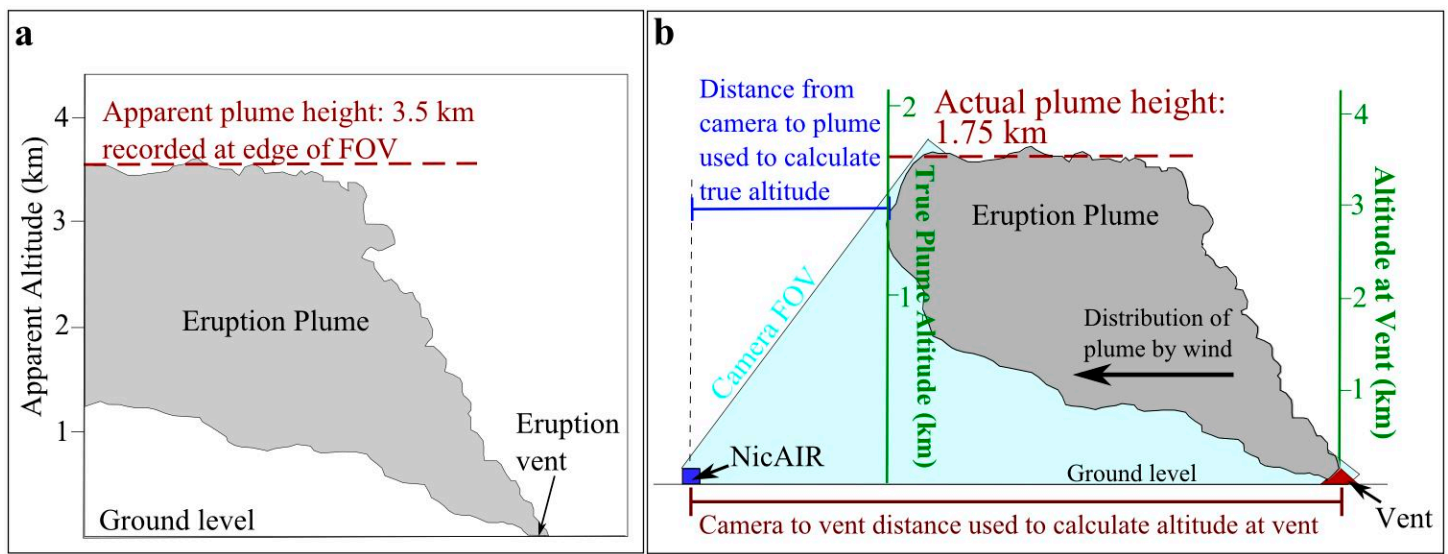

Figure 5. Actual cloud height derived from apparent cloud height and cloud location. (a) Schematic field of view from the perspective of the camera showing apparent plume height and (b) schematic side-view illustrating the effect of transport towards the camera on actual versus apparent plume height.

In order to determine the location of the cloud in relation to the camera, wind dispersal of the cloud was analyzed from meteorological data. Meteorological conditions at the approximate height of the eruption cloud above sea level at the eruption site were extracted from the HARMONIE model and radiosonde data. The HARMONIE meteorological model predicted weather conditions for the eruption site every hour, providing detailed modeled data. Radiosonde data from the Egilsstaðir weather station (located $\sim 120 \mathrm{~km}$ east north east of the eruption site) provided measurements but at a low temporal resolution (measurements once every $24 \mathrm{~h}$ ). Wind directions from both were used, depending on the visual analysis of the cloud distribution in the NicAIR data.

For each hour of averaged apparent cloud height, the wind direction was mapped out in relation to the bearing of the camera line of sight to the vent, and the angle between the two directions was calculated. The NicAIR camera FOV was considered as a cone, where the cloud at the edge of the FOV may be considered as being located somewhere along the edge of the FOV cone. By combining the wind direction and the bearing of the camera line of sight, the approximate location of the apparent cloud height was estimated. The distance between the camera and the apparent cloud height location was then determined and new pixel heights were calculated using this new distance. The new pixel heights were combined with the average hourly apparent cloud height to give the actual cloud height as recorded by the NicAIR camera (Figure $5 b$ ).

\subsection{Observations from Ground and Aircraft}

Observations were made throughout the eruption by scientists working at the eruption site and scientists making airborne observations from the TF-FMS and TF-SIF aircrafts, owned by Isavia and the Icelandic Coast Guard, respectively. Visual observations of eruption cloud height made by scientists in the field were intended to be the maximum eruption cloud height. These ground-based observations were recorded in their field notes and/or were called into IMO. The airborne observations were called into IMO and stored in its database. 


\section{Results}

\subsection{Eruption Cloud Composition}

\subsubsection{Gases}

The average daily value of $\mathrm{SO}_{2}$ flux measured by DOAS is in Table 1 , and the time series of the measurements throughout the eruption, linearly interpolated between measurement dates, is shown in Figure 6. The total over the duration of the eruption is calculated to be $9.6 \mathrm{Mt} \mathrm{SO}_{2}$ with an uncertainty of $-50-+30 \%$, or $6.7-14.3 \mathrm{Mt} \mathrm{SO}_{2}$. The average emission rate during the eruption is $610 \mathrm{~kg} / \mathrm{s}$, with an uncertainty of $430-920 \mathrm{~kg} / \mathrm{s}$. The maximum daily average emission rate during the eruption was in excess of $2100 \mathrm{~kg} / \mathrm{s}$ and the maximum high-quality scan included in the data set was in excess of $5500 \mathrm{~kg} / \mathrm{s}$. The overall trend of the eruption was a decrease in emissions of $\mathrm{SO}_{2}$ as the eruption progressed (September 2014-February 2015), with the exception of November 2014, when higher emission rates alternated with lower ones. The total of the emissions over the duration of the eruption is less than, but within the uncertainty of, the $11.8 \pm 4 \mathrm{Mt}$ previously published in [1]. This previous publication only included the ring-road traverses (marked as Ring in Table 1).

The post-eruptive outgassing of the lava field remained above detection limits by the ScanDOAS instruments for three months following the end of the eruption. During these three months, the average post-eruption outgassing of $\mathrm{SO}_{2}$ was $3 \pm 1.9 \mathrm{~kg} / \mathrm{s}$. The post-eruptive degassing, interpolated for the three months, equals $24 \mathrm{kt} \mathrm{SO}_{2}$ [14], which is less than $1 \%$ of the degassing during the eruption.

Table 1. Daily average DOAS measurements of $\mathrm{SO}_{2}$ flux, distinguished by measurement technique and if the measurement occurred during or after the eruption.

\begin{tabular}{|c|c|c|c|}
\hline $\begin{array}{c}\text { Date } \\
\text { (DDMMYY) }\end{array}$ & $\mathrm{SO}_{2}$ Flux (kg/s) & Technique & Syn- or Post-Eruption \\
\hline $02 / 09 / 2014$ & $520 \pm 100$ & Scan & Syn \\
\hline $08 / 09 / 2014$ & $1330 \pm 440$ & Scan & Syn \\
\hline $10 / 09 / 2014$ & $1050 \pm 370$ & Scan & Syn \\
\hline $11 / 09 / 2014$ & $1140 \pm 230$ & Scan & Syn \\
\hline $12 / 09 / 2014$ & $1290 \pm 290$ & Scan & Syn \\
\hline $13 / 09 / 2014$ & $1120 \pm 220$ & Scan & Syn \\
\hline $14 / 09 / 2014$ & $610 \pm 180$ & Scan & Syn \\
\hline $18 / 09 / 2014$ & $820 \pm 310$ & Near & Syn \\
\hline $19 / 09 / 2014$ & $250 \pm 100$ & Near & Syn \\
\hline $20 / 09 / 2014$ & $680 \pm 260$ & Near & Syn \\
\hline $21 / 09 / 2014$ & $2170 \pm 1720$ & Near; Ring & Syn \\
\hline $22 / 09 / 2014$ & $1130 \pm 490$ & Scan & Syn \\
\hline $24 / 09 / 2014$ & $710 \pm 210$ & Scan & Syn \\
\hline $25 / 09 / 2014$ & $960 \pm 320$ & Scan & Syn \\
\hline $30 / 09 / 2014$ & $1200 \pm 230$ & Scan & Syn \\
\hline $01 / 10 / 2014$ & $1180 \pm 240$ & Scan & Syn \\
\hline $02 / 10 / 2014$ & $840 \pm 460$ & Scan & Syn \\
\hline $06 / 10 / 2014$ & $890 \pm 340$ & Ring & Syn \\
\hline $05 / 11 / 2014$ & $1450 \pm 550$ & Ring & Syn \\
\hline $18 / 11 / 2014$ & $220 \pm 30$ & Scan & Syn \\
\hline $21 / 11 / 2014$ & $1070 \pm 410$ & Ring & Syn \\
\hline $25 / 11 / 2014$ & $250 \pm 50$ & Scan & Syn \\
\hline $26 / 11 / 2014$ & $990 \pm 1810$ & Scan & Syn \\
\hline $02 / 12 / 2014$ & $300 \pm 110$ & Scan & Syn \\
\hline $21 / 01 / 2015$ & $250 \pm 50$ & Scan; Near & Syn \\
\hline $22 / 01 / 2015$ & $410 \pm 70$ & Scan & Syn \\
\hline $25 / 01 / 2015$ & $520 \pm 120$ & Scan & Syn \\
\hline $27 / 01 / 2015$ & $320 \pm 100$ & Scan & Syn \\
\hline $30 / 01 / 2015$ & $40 \pm 20$ & Ring & Syn \\
\hline $31 / 01 / 2015$ & $410 \pm 160$ & Ring & Syn \\
\hline
\end{tabular}


Table 1. Cont.

\begin{tabular}{cccc}
\hline $\begin{array}{c}\text { Date } \\
\text { (DDMMY) }\end{array}$ & SO $_{\mathbf{2}}$ Flux $(\mathbf{k g} / \mathbf{s})$ & Technique & Syn- or Post-Eruption \\
\hline $04 / 02 / 2015$ & $240 \pm 90$ & Ring & Syn \\
$06 / 02 / 2015$ & $220 \pm 30$ & Scan & Syn \\
$16 / 02 / 2015$ & $90 \pm 30$ & Scan & Syn \\
$07 / 03 / 2015$ & $2 \pm 0.5$ & Scan & Post \\
$13 / 03 / 2015$ & $1 \pm 0.2$ & Scan & Post \\
$21 / 03 / 2015$ & $2 \pm 0.5$ & Scan & Post \\
$22 / 03 / 2015$ & $2 \pm 0.5$ & Scan & Post \\
$26 / 03 / 2015$ & $2 \pm 0.5$ & Scan & Post \\
$27 / 03 / 2015$ & $2 \pm 0.5$ & Scan & Post \\
$28 / 03 / 2015$ & $3 \pm 0.7$ & Scan & Post \\
$15 / 04 / 2015$ & $4 \pm 1$ & Scan & Post \\
$22 / 05 / 2015$ & $4 \pm 1$ & Scan & Post \\
$23 / 05 / 2015$ & $4 \pm 1$ & Scan & Post \\
$24 / 05 / 2015$ & $5 \pm 1$ & Scan & \\
\hline
\end{tabular}

Scan = ScanDOAS; Near = near-lava traverses and near-lava scan; Ring = ring-road traverses.

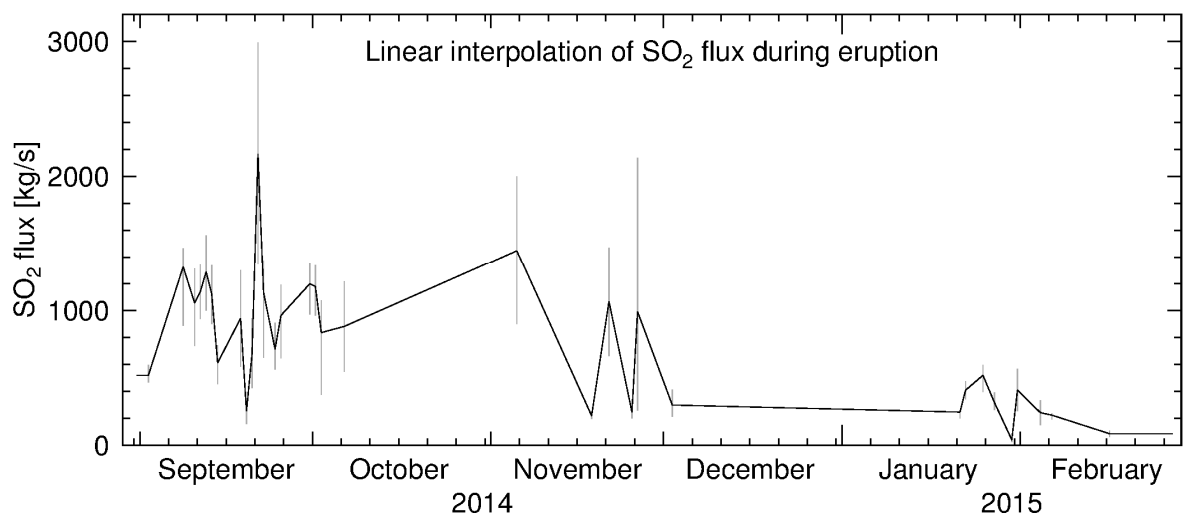

Figure 6. Time series of the daily average $\mathrm{SO}_{2}$ flux measured by DOAS connected with a solid black line showing the linear interpolation of the data between measurement dates. The gray vertical bars show the uncertainty for each day.

The $\mathrm{SO}_{2}$ peaks measured down-wind by the car-mounted in situ instrument and the atmospheric column amount measured by the MobileDOAS were sometimes concurrent and sometimes shifted from one another (Figure 7). These measurements are shown as raw data, where the baseline of the measurements has not been shifted to zero. Sometimes the traverses needed to be extremely long, up to two hours driving time, to obtain a measurement of background clean air (undetectable $\mathrm{SO}_{2}$ ) before and after both instruments detected $\mathrm{SO}_{2}$. Due to the short daylight in winter, only three hours of daylight on the shortest day of the year in the north of Iceland, some attempted traverses were not completed.

The changes in the gas ratios measured by OP-FTIR, MultiGAS, and filter pack over the duration of the eruption are seen in Figure 8. Exponential trends are only seen for $\mathrm{CO}_{2} / \mathrm{SO}_{2}\left(\mathrm{R}^{2}=0.43\right)$, $\mathrm{H}_{2} \mathrm{O} / \mathrm{CO}_{2}\left(\mathrm{R}^{2}=0.47\right)$, and $\mathrm{SO}_{2} / \mathrm{H}_{2} \mathrm{~S}\left(\mathrm{R}^{2}=0.78\right)$. For $\mathrm{CO}_{2}$ we utilize this trend to calculate the emission of $\mathrm{CO}_{2}$ relative to $\mathrm{SO}_{2}$. Using the exponential change for the $\mathrm{SO}_{2} / \mathrm{H}_{2} \mathrm{~S}$ ratio is not appropriate, because while there is an excellent fit, this fit is based on only four measurements which were all made at the beginning of the eruption. The extrapolation to the rest of the eruption is not grounded in measurements. In the absence of a trend, but with the high variance observed in the gas ratios, for $\mathrm{H}_{2} \mathrm{O}, \mathrm{HCl}$, and $\mathrm{HF}$, as well as for $\mathrm{H}_{2} \mathrm{~S}$, we calculate the gas ratios using the $25-75 \%$ percentiles of the data (Table 2). We then calculate the emissions over the duration of the eruption of the non- $\mathrm{SO}_{2}$ gases based on this range of ratios and the emission rate of $\mathrm{SO}_{2}$ extrapolated from the DOAS measurements (Table 2). 

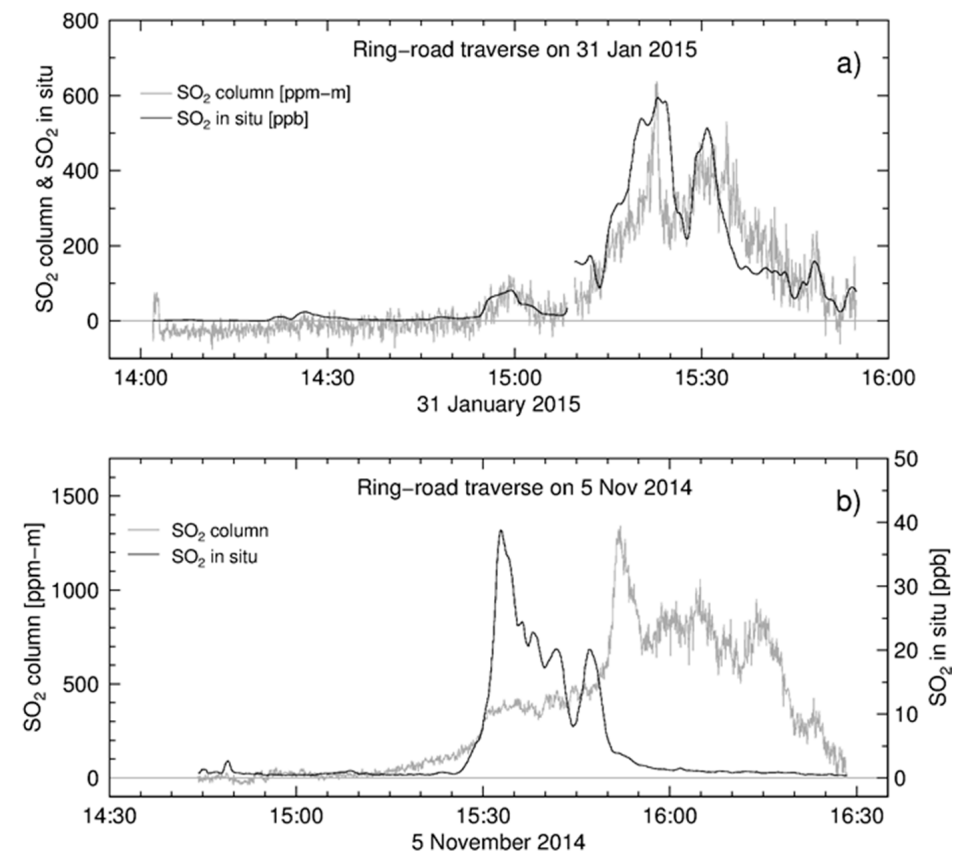

Figure 7. Examples of ring-road traverses with concurrent MobileDOAS $\mathrm{SO}_{2}$ column and in situ $\mathrm{SO}_{2}$ measurements. (a) 31/01/15 with peaks corresponding very closely and (b) 05/11/14 with incongruent peaks.
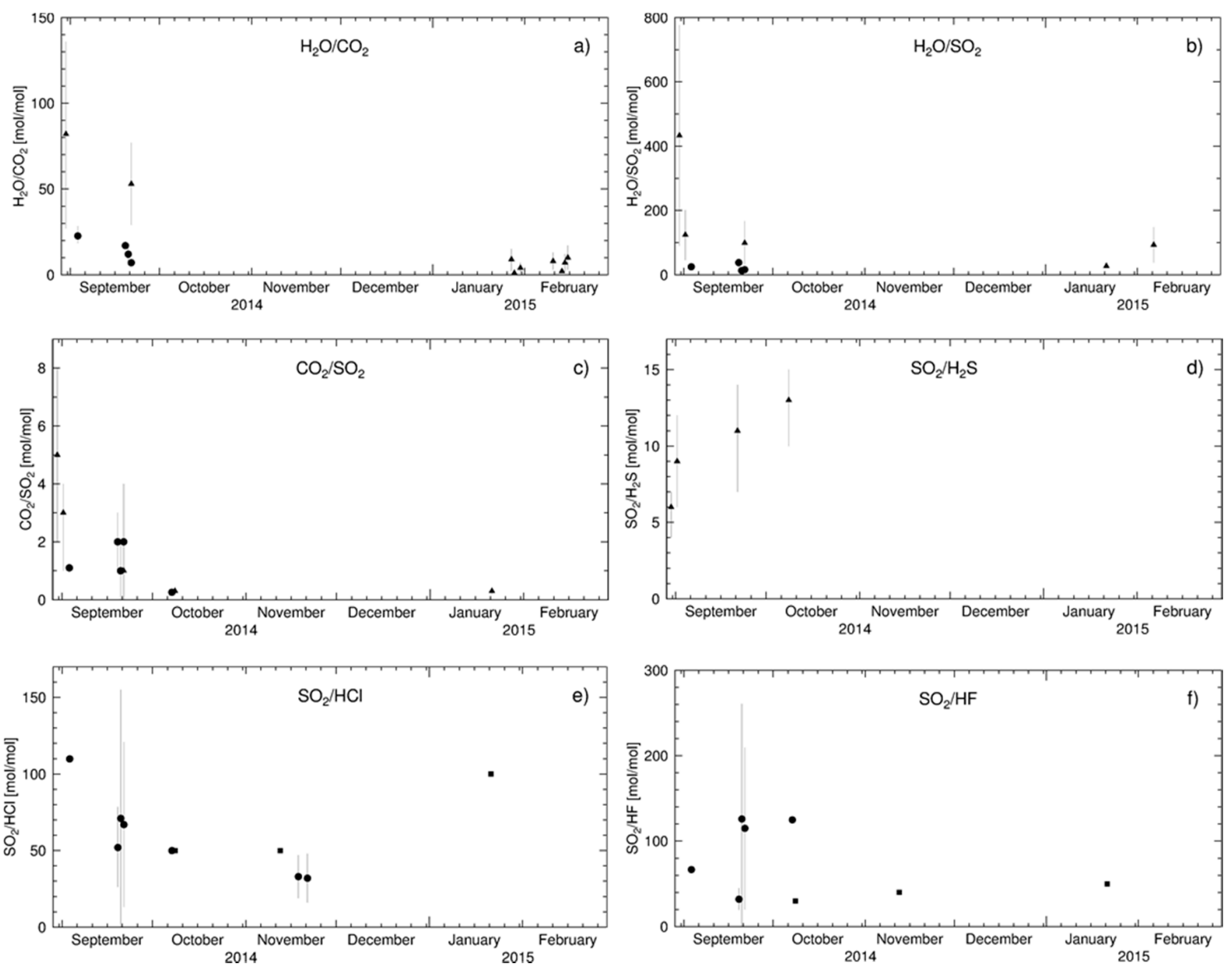

Figure 8. The time series of daily averaged gas ratios (a) $\mathrm{H}_{2} \mathrm{O} / \mathrm{CO}_{2}$; (b) $\mathrm{H}_{2} \mathrm{O} / \mathrm{SO}_{2}$; (c) $\mathrm{CO}_{2} / \mathrm{SO}_{2}$; (d) $\mathrm{SO}_{2} / \mathrm{H}_{2} \mathrm{~S}$; (e) $\mathrm{SO}_{2} / \mathrm{HCl}$; (f) $\mathrm{SO}_{2} / \mathrm{HF}$. Measurements made by OP-FTIR, MultiGAS, and Filter Pack are shown as circles, triangles, and squares, respectively. Vertical gray bars indicate uncertainty. 
Table 2. Representative gas ratios over the duration of the eruption and the calculated emission of each gas relative to $\mathrm{SO}_{2}$ based on the DOAS flux rate of $9.6 \mathrm{Mt} \mathrm{SO}_{2}$ and in parentheses with the uncertainty range of 6.7-14.3 $\mathrm{Mt} \mathrm{SO}_{2}$.

\begin{tabular}{ccc}
\hline Gas Ratios (Mol/Mol) & $\mathbf{2 5 \% - 7 5 \% ~ P e r c e n t i l e s ~}$ & Emissions (Mt) \\
\hline $\mathrm{H}_{2} \mathrm{O} / \mathrm{CO}_{2}$ & $5-16$ & \\
$\mathrm{H}_{2} \mathrm{O} / \mathrm{SO}_{2}$ & $18-98$ & $\mathrm{H}_{2} \mathrm{O}: 49-263(34-394)$ \\
$\mathrm{CO}_{2} / \mathrm{SO}_{2}$ & $0.3-2$ & $\mathrm{CO}_{2}: 5.1(3.6-7.6)$ \\
$\mathrm{SO}_{2} / \mathrm{H}_{2} \mathrm{~S}$ & $9-13$ & $\mathrm{H}_{2} \mathrm{~S}: 0.4-0.6(0.3-0.9)$ \\
$\mathrm{SO}_{2} / \mathrm{HCl}$ & $46-79$ & $\mathrm{HCl}: 0.07-0.1(0.05-0.2)$ \\
$\mathrm{SO}_{2} / \mathrm{HF}$ & $34-122$ & $\mathrm{HF}: 0.02-0.09(0.02-0.1)$ \\
\hline
\end{tabular}

\subsubsection{Particles}

Minor tephra production and fall out, including Pele's hair, was reported by scientists in the field during the first week of the eruption.

The monthly mean OPC particle count measurements during the Holuhraun eruption, October 2014-February 2015, ranged from $6.12 \times 10^{4}-1.17 \times 10^{5} \mathrm{~cm}^{-3}\left(14-69 \mu \mathrm{g} / \mathrm{m}^{3}\right)$, with the greatest measured in December 2014 and the least in October 2014. The maximum instantaneous concentration was recorded in December 2014 with $4.52 \times 10^{6} \mathrm{~cm}^{-3}\left(162 \mu \mathrm{g} / \mathrm{m}^{3}\right)$. The highest concentrations were relatively short lived and daily averages remained quite consistent. In the five months following the eruption, March-July 2015, the monthly means were very similar to the values measured during the eruption $\left(4.81 \times 10^{4}-7.86 \times 10^{4} \mathrm{~cm}^{-3}\right)$. Comparing the measurements made during and after the eruption, there was no increase in the strength of individual maxima or the frequency of maxima.

All filter pack samples except one were collected on the ground. The filter pack samples showed very low masses of particles, except for the airborne sample collected in the eruption cloud. With the exception of this one sample, the mass of particles remained relatively constant $\left(57-191 \mu \mathrm{g} / \mathrm{m}^{3}\right)$, regardless of the mass of $\mathrm{SO}_{2}\left(5-4300 \mu \mathrm{g} / \mathrm{m}^{3}\right)$ collected on the gas filters. The particle concentrations collected on the ground-based filter packs were slightly enhanced relative to the particle concentrations measured by the continuous OPC both during and after the eruption. For the airborne sample, the mass ratio of $\mathrm{SO}_{2}$ / particles was 2 .

The radar network intermittently detected the eruption cloud. This manifested in the radar data as a cloud with increased values of reflectivity (displayed as maximum dBZ) up to $30 \mathrm{dBZ}$ that persisted close to the eruption site (Figure 9). Meteorological clouds were also detected by the radar during the eruption period as clusters of higher reflectivity that were dynamically transported by winds. An increase in reflectivity can be due to droplets, such as are found in meteorological clouds or eruption-induced droplets [41], and particles, such as ice, volcanic ash [42,43], or suspended dust [44]. The radar-detected eruption cloud was often enhanced by precipitation, and sometimes formed a precipitating cloud in the absence of other weather clouds in the region. When the eruption cloud was enhanced by transitory precipitating clouds, these clouds would move above the eruption site and a cloud would develop over the eruption site, and this cloud would continue to be visible after the meteorological clouds had moved past. The eruption cloud was most consistently observed by the C-band radar at Fljótsdalsheiði. This often showed the cloud in the layer of the atmosphere closest to the ground, which at the distance from the radar to the eruption site, means within the lowest $1 \mathrm{~km}$ of the atmosphere. The cloud was most frequently observed during low wind speeds and when there was a change in wind direction, and often in the morning. A persistent cloud above the eruption site remained detectable by the radar after the end of the eruption (Figure $9 d, e$ ), when the lava field continued to give off heat and to outgas. The reflectivity of the radar-detectable eruption cloud was greatest at the start of the eruption, and became weaker later in the eruption and in the post-eruptive period. 

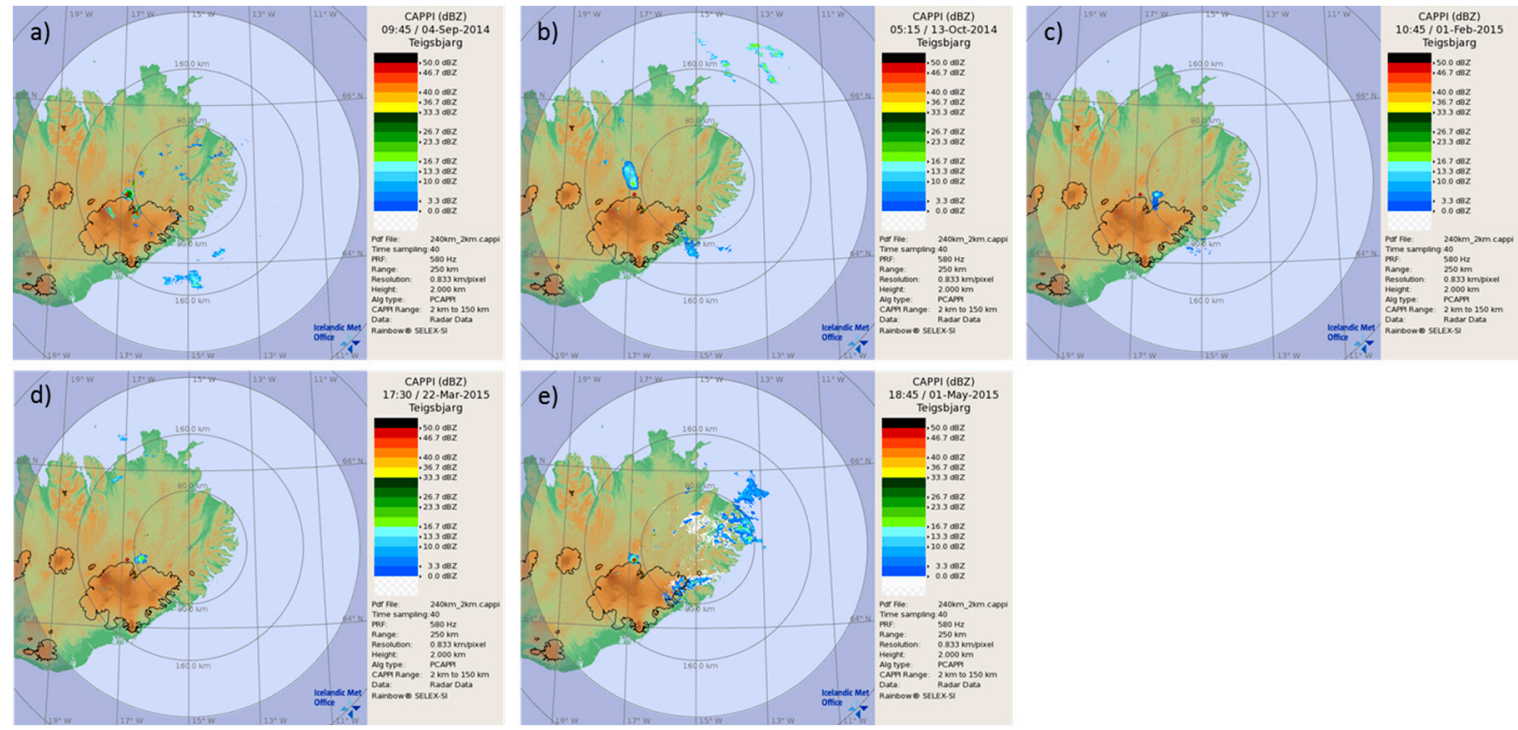

Figure 9. The radar-detectable cloud above the eruption site (indicated in red) detected by the C-band radar at Fljótsdalsheiði. (a) 04/09/14; (b) 13/10/14; (c) 01/02/15; (d) 22/03/15; (e) 01/05/15.

\subsection{Cloud Height}

The daily average, minimum, and maximum of the height of the top of the eruption cloud measured by ground- and aircraft-based observations, web cam, ScanDOAS, MobileDOAS, and NICAIR II IR camera are found in Table 3. The ScanDOAS and MobileDOAS approaches, however, do not provide the height of the top of the cloud, but rather the height of the center of mass of the cloud, so all days including these techniques will be under-detections of the top of cloud height. In general, the start of the eruption was the strongest with the highest cloud heights, and then for the duration of the eruption, until the end, the height varied mainly between 1-3 km agl. The variance of the daily averages is high. A diurnal variation was evident with higher maximum cloud heights in the afternoons, indicating that atmospheric stability was influencing the volcanic cloud [45]. On 22 January 2015, a balloon was launched carrying a miniature optical particle counter [32]. The balloon-borne particle counter found the top of the eruption cloud to be between 2.7 and $3.1 \mathrm{~km}$, which is in excellent agreement with the average value of $2.8 \mathrm{~km}$ made by field observations on this day.

Table 3. Observations of height of eruption cloud made by ground- and aircraft-based observations, web camera, ScanDOAS, MobileDOAS, and NICAIR II IR camera.

\begin{tabular}{ccccc}
\hline $\begin{array}{c}\text { Date } \\
\text { (DDYYMM) }\end{array}$ & $\begin{array}{c}\text { Daily Average Top } \\
\text { of Cloud Height } \\
(\mathbf{k m} \cdot \mathbf{A G L})\end{array}$ & $\begin{array}{c}\text { Daily Min Top of } \\
\text { Cloud Height } \\
\mathbf{( k m \cdot A G L )}\end{array}$ & $\begin{array}{c}\text { Daily Max Top of } \\
\text { Cloud Height } \\
(\mathbf{k m} \cdot \mathbf{A G L )}\end{array}$ & Technique \\
\hline $29 / 08 / 2014$ & 1.0 & & & Cam \\
$01 / 09 / 2014$ & 4.5 & & 6.0 & Flight \\
$03 / 09 / 2014$ & 5.3 & 4.5 & 5.5 & Flight \\
$04 / 09 / 2014$ & 4.1 & 1.7 & & Field; DOAS \\
$05 / 09 / 2014$ & 3.8 & & & Field \\
$06 / 09 / 2014$ & 3.1 & & 4.3 & Field \\
$07 / 09 / 2014$ & 3.5 & 1.9 & 3.7 & Field \\
$08 / 09 / 2014$ & 3.0 & 1.3 & 2.5 & DOAS \\
$09 / 09 / 2014$ & 2.1 & 1.2 & 3.1 & DOAS \\
$10 / 09 / 2014$ & 1.6 & 1.1 & 2.7 & DOAS \\
$11 / 09 / 2014$ & 2.0 & 1.3 & Cam; DOAS \\
$12 / 09 / 2014$ & 1.8 & & & Cam; DOAS \\
\hline
\end{tabular}


Table 3. Cont.

\begin{tabular}{|c|c|c|c|c|}
\hline $\begin{array}{c}\text { Date } \\
\text { (DDYYMM) }\end{array}$ & $\begin{array}{c}\text { Daily Average Top } \\
\text { of Cloud Height } \\
(\mathrm{km} \cdot \mathrm{AGL})\end{array}$ & $\begin{array}{c}\text { Daily Min Top of } \\
\text { Cloud Height } \\
(\mathrm{km} \cdot \mathrm{AGL})\end{array}$ & $\begin{array}{c}\text { Daily Max Top of } \\
\text { Cloud Height } \\
(\mathbf{k m} \cdot A G L)\end{array}$ & Technique \\
\hline $13 / 09 / 2014$ & 2.6 & 1.6 & 3.5 & Cam; Flight; Field; DOAS \\
\hline $14 / 09 / 2014$ & 2.3 & 2.0 & 2.5 & Cam; Field; DOAS \\
\hline $15 / 09 / 2014$ & 1.6 & & & Cam \\
\hline $16 / 09 / 2014$ & 2.3 & & & Cam \\
\hline $17 / 09 / 2014$ & 2.0 & & & Cam \\
\hline $19 / 09 / 2014$ & 3.0 & & & Field \\
\hline $20 / 09 / 2014$ & 2.3 & & & Cam; Field \\
\hline $21 / 09 / 2014$ & 1.6 & 1.0 & 2.0 & Cam; Field; Mobile \\
\hline $22 / 09 / 2014$ & 2.5 & 2.1 & 3.0 & Cam; Flight; Field \\
\hline $23 / 09 / 2014$ & 3.9 & 3.5 & 4.2 & Field \\
\hline $24 / 09 / 2014$ & 2.1 & 1.9 & 2.8 & Field; DOAS \\
\hline $26 / 09 / 2014$ & 2.0 & & & Field \\
\hline $27 / 09 / 2014$ & 2.5 & & & Field \\
\hline $28 / 09 / 2014$ & 3.0 & & & Field \\
\hline $02 / 10 / 2014$ & 1.7 & & & Field \\
\hline $06 / 10 / 2014$ & 1.2 & & & Mobile \\
\hline $08 / 10 / 2014$ & 1.0 & & & Field \\
\hline $17 / 10 / 2014$ & 2.6 & 2.4 & 3.0 & Flight; Field \\
\hline $21 / 10 / 2014$ & 1.3 & & & Field \\
\hline $22 / 10 / 2014$ & 1.2 & & & Field \\
\hline $23 / 10 / 2014$ & 1.2 & & & Field \\
\hline $28 / 10 / 2014$ & 2.0 & & & Field \\
\hline $29 / 10 / 2014$ & 2.6 & 1.8 & 3.5 & Field \\
\hline $30 / 10 / 2014$ & 2.7 & 2.3 & 2.9 & Field \\
\hline $04 / 11 / 2014$ & 2.9 & 2.8 & 3.0 & Flight \\
\hline $05 / 11 / 2014$ & 1.4 & 1.0 & 1.5 & Field; Mobile \\
\hline $11 / 11 / 2014$ & 2.2 & 1.3 & 3.0 & Field \\
\hline $13 / 11 / 2014$ & 3.5 & & & Field \\
\hline $14 / 11 / 2014$ & 2.8 & 2.5 & 3.0 & Flight \\
\hline $18 / 11 / 2014$ & 1.7 & 0.4 & 2.3 & Flight; Field \\
\hline $19 / 11 / 2014$ & 1.3 & 1.1 & 1.5 & Field \\
\hline $20 / 11 / 2014$ & 1.0 & 0.5 & 1.4 & Field \\
\hline $21 / 11 / 2014$ & 0.8 & 0.5 & 1.5 & Field; Mobile \\
\hline $23 / 11 / 2014$ & 2.1 & 1.9 & 2.2 & NICAIRII \\
\hline $24 / 11 / 2014$ & 0.5 & & & NICAIRII \\
\hline $25 / 11 / 2014$ & 2.6 & 0.8 & 4.0 & Field; NICAIRII \\
\hline $26 / 11 / 2014$ & 1.8 & 0.4 & 3.1 & Field; NICAIRII \\
\hline $27 / 11 / 2014$ & 1.9 & 0.9 & 3.1 & Field \\
\hline $30 / 11 / 2014$ & 2.5 & 2.4 & 2.6 & NICAIRII \\
\hline $01 / 12 / 2014$ & 1.0 & & & NICAIRII \\
\hline $02 / 12 / 2014$ & 2.5 & & & Field \\
\hline $03 / 12 / 2014$ & 1.3 & & & Field \\
\hline $04 / 12 / 2014$ & 2.1 & 1.5 & 2.7 & Flight; Field \\
\hline 05/12/2014 & 2.0 & 1.6 & 2.3 & Field \\
\hline 09/12/2014 & 0.5 & & & NICAIRII \\
\hline $30 / 12 / 2014$ & 2.6 & 2.5 & 2.7 & Flight \\
\hline $10 / 01 / 2015$ & 2.5 & & & Flight \\
\hline $21 / 01 / 2015$ & 3.5 & 3.0 & 4.2 & Mobile \\
\hline $22 / 01 / 2015$ & 2.8 & 2.8 & 2.8 & Field \\
\hline $27 / 01 / 2015$ & 1.3 & & & Field \\
\hline $28 / 01 / 2015$ & 1.4 & 1.3 & 1.5 & Field \\
\hline $29 / 01 / 2015$ & 2.8 & 2.3 & 3.2 & Field \\
\hline $30 / 01 / 2015$ & 0.7 & 0.5 & 1.0 & Mobile \\
\hline $31 / 01 / 2015$ & 1.7 & 1.5 & 2.0 & Mobile \\
\hline $03 / 02 / 2015$ & 1.5 & & & Flight \\
\hline $04 / 02 / 2015$ & 0.9 & 0.7 & 1.0 & Mobile \\
\hline $19 / 02 / 2015$ & 0.9 & 0.7 & 1.0 & Field \\
\hline
\end{tabular}

Cam = Webcam; Flight $=$ Aircraft observations; Field = Ground-based observations; DOAS = two ScanDOAS triangulation; Mobile $=$ MobileDOAS peaks with HARMONIE winds; NICAIRII = NICAIRII IR Camera. 


\section{Discussion}

The $\mathrm{SO}_{2}$ flux from Holuhraun was enormous at the start of the eruption (an average during September 2014 of $1007 \mathrm{~kg} / \mathrm{s}$ ) and diminished over the course of the eruption as shown by our ground-based measurements. An exponential decay curve fit to the $\mathrm{SO}_{2}$ flux measurements gives an $\mathrm{R}^{2}=0.38$, as there are days with high emissions that do not follow a simple decay. An exponential decay has been identified as characterizing the rate of change of the Bárðarbunga caldera volume, which was directly associated with the mass eruption rate at Holuhraun during the six months of the eruption [25]. The rate of lava effusion, based on the thermal emissivity of the lava field, similarly exponentially decayed like the caldera volume change, until a rapid cessation during the last month of the eruption [46].

The gas flux can deviate from the eruption vigor (such as lava effusion rate) if there is a change in the physical processes responsible for releasing $\mathrm{SO}_{2}$ into the atmosphere and/or if there is a change in the composition of the magma. Few of the atmospheric measurements of $\mathrm{SO}_{2}$ ratio relative to other gas species have a statistically significant trend over the course of the eruption, although the $\mathrm{CO}_{2} / \mathrm{SO}_{2}$ ratio does exponentially decay in a coherent, albeit statistically weak, fashion. As there is no systematic change in melt inclusion compositions measured over the course of the eruption [47], physical processes related to $\mathrm{SO}_{2}$ degassing are therefore considered a likely contributor to the discrepancy between the $\mathrm{SO}_{2}$ flux rate and other qualities of the eruption such as the lava effusion rate and thermal emissivity.

$\mathrm{SO}_{2}$ measured in the cloud was released from magma as it rose through the conduit and erupted at the vent; from non-erupted magma; and from the lava flow during and after emplacement [14]. The degassing of the erupted magma is expected to follow the same curve as the lava effusion rate; gas emitted from non-erupted magma and the lava flow would contribute to deviations from this trend.

Fracturing and cracking of the lava facilitates gas release, and can increase outgassing from the lava flow [14]. The lava outgassing can persist for months after the lava is emplaced, and outgassing from lava can be episodic, affected by variable rates of lava fractionation. In the first phase of the eruption, 31 August-12 October, 2014, the lava dynamically changed between 'a'à and slabby and rubbly pāhoehoe lava types [48]. These continuous changes in lava texture, with the more fractured lava facilitating the release of gases, are potentially responsible for some of the high variance in the $\mathrm{SO}_{2}$ flux data set. The second phase of the eruption, 12 October-30 November, 2014, was distinguished by the presence of a continually replenished lava lake, which is considered to be the supply for the lava flow [48]. There are six measurements in November and early December, alternating with high emissions of $\mathrm{SO}_{2}$ (average $1169 \mathrm{~kg} / \mathrm{s}$ on 5, 21, and 26 November) and low emissions (average $254 \mathrm{~kg} / \mathrm{s}$ on 18, 25 November and 2 December), when there was no corresponding changes in the lava effusion rate or eruption intensity. The high values could be due to the contribution of outgassing from the lava lake overprinting the decay of emissions originating from the erupted magma. The $\mathrm{SO}_{2}$ fluxes are therefore not reflecting solely the deep magmatic system: they also are affected by surface processes.

The total amount of $\mathrm{SO}_{2}$ emitted by the eruption reported here is $9.6 \mathrm{Mt}$, which is less than, but within the uncertainty, of the $11.8 \pm 4 \mathrm{Mt}$ previously reported [1]. The very few measurements made in winter make the interpolated sum of emissions over the entire eruption very sensitive to two measurement days. The very low value of the last measurement day in December 2014 connected with the very low value of the first measurement day at the end of January makes the sum over the six months significantly lower than it would be if these had been higher values. The ScanDOAS measurements and near-lava traverses were often saturated and there were significant impacts, which also affected the long-distance traverses, from the scattering of light within and outside of the eruption cloud [9]. The daily-average fluxes, and therefore the sum over the eruption, should be interpreted as under-detections, with the near-source scans and traverses under-detecting the most. The ring-road traverses measured a more dilute cloud, however they were too infrequent to capture the true variance in emissions during the eruption. There were huge variations in $\mathrm{SO}_{2}$ flux throughout each day and between different days. A traverse is a snapshot measurement and therefore not necessarily representative of the average for a longer time range. We therefore consider the full data set, with its 
far greater number of flux measurements, to provide a more accurate basis for calculating the sum of emissions over the duration of the six-month long eruption, rather than relying on a smaller subset of data including only the ring-road traverses. Near-lava traverse measurements were made when the meteorological conditions were optimal. Labor-intensive data processing was, however, necessary to account for the optical-thickness and scattering. The improved automation of DOAS in Iceland during the dark winter months, so as to minimize the time when UV measurements are impossible, requires the development of improved data processing techniques.

During the first months of the eruption, the emissions rates were greatest, the eruption cloud was highest in elevation, and satellite-borne instruments were most sensitive to the emissions. We therefore use measurements from this time to compare the ground-based DOAS measurements with satellite-derived $\mathrm{SO}_{2}$ fluxes. Infrared Atmospheric Sounding Interferometer (IASI) and Ozone Monitoring Instrument (OMI) $\mathrm{SO}_{2}$ mass burdens were integrated with simulations made with the Numerical Atmospheric-dispersion Modeling Environment (NAME) in [49]. This approach provides a total emission during September of $2.0 \pm 0.6 \mathrm{Mt} \mathrm{SO}_{2}$, while our ground-based measurements, linearly interpolated between days without measurements, find a total emission of $2.5(1.8-3.8) \mathrm{Mt} \mathrm{SO}_{2}$ during September. Thermal infrared (TIR) data from MSG-SEVIRI is used in [31] to calculate a time-averaged $\mathrm{SO}_{2}$ mass flux. They report a total emission for 01 September-25 November of $8.9 \pm 0.3 \mathrm{Mt} \mathrm{SO}_{2}$, while our ground-based measurement approach finds 7.3 (5.1-11.0) $\mathrm{Mt} \mathrm{SO}_{2}$ over this same time period. Both the satellite and ground-based approaches have explanations for why the measurements should be viewed as minimum values, and all agree within the uncertainty of each approach. Only the ground-based DOAS instruments were able to make measurements of $\mathrm{SO}_{2}$ flux throughout the eruption and in the post-eruptive outgassing period.

The ground-based measurements of the $\mathrm{SO}_{2} \mathrm{flux}$, despite the significant temporal gaps, were important for the initialization of the gas dispersion model used for real-time forecasts and warnings during the eruption. As we improve our measurement and data processing techniques, this data will be used ever more reliably for this important mitigation tool.

The 9.6 Mt of $\mathrm{SO}_{2}$ emitted during six months of eruption are extraordinary. Since 1978, UV satellites have been used to quantify $\mathrm{SO}_{2}$ emissions from volcanic eruptions [50]. Only the explosive dacitic eruption of Pinatubo in 1991 released more $\mathrm{SO}_{2}$ than this eruption on an annual basis. The Holuhraun eruption is the effusive eruption with the highest emissions of $\mathrm{SO}_{2}$ in this annually-based record. Hawaii Island's Kilauea Volcano has erupted continuously since January 1983, with sporadic eruptive behavior preceding this. USGS measurements show a sum over the period 1979-1997 of 9.45-9.93 $\mathrm{Mt} \mathrm{SO}_{2}$ [51], approximately what Holuhraun emitted in six months. The Kilauea eruption has emitted more $\mathrm{SO}_{2}$ than the Holuhraun eruption over a much longer time. Within Iceland, a total of $0.06 \mathrm{Mt}$ of anthropogenic $\mathrm{SO}_{2}$ was emitted in 2015 [52]. The emissions of $\mathrm{CO}_{2}$ from Holuhraun are also substantial. A total of $5.1 \mathrm{Mt} \mathrm{CO}_{2}$ is calculated to have been emitted during the eruption, while within Iceland in 2015, a total of $3 \mathrm{Mt}$ of anthropogenic $\mathrm{CO}_{2}$ was emitted [52].

The $\mathrm{SO}_{2} / \mathrm{HF}$ molar ratio measured in the Holuhraun eruption cloud was 109-392. This is quite high: most $\mathrm{SO}_{2} / \mathrm{HF}$ ratios measured at volcanoes around the world exhibit much lower ratios (i.e., are richer in HF). Many papers, including [53-62], report values significantly less than those measured during the Holuhraun eruption with the exception of Kilauea $\mathrm{Pu}$ 'O with an $\mathrm{SO}_{2} / \mathrm{HF}$ molar ratio of 108 and Poás volcano with 190-greater than 200 (important to note that Poás is in a very different setting than Bárðarbunga). Despite the prolific gas-rich nature of the eruption, precipitation samples collected around the country show that the majority of the $\mathrm{Cl}$ in the samples came from sea spray as opposed to the volcanic eruption cloud [30]. This was a gas-rich but halogen-poor eruption.

The $\mathrm{H}_{2} \mathrm{O} / \mathrm{CO}_{2}$ and $\mathrm{H}_{2} \mathrm{O} / \mathrm{SO}_{2}$ ratios tend to show higher $\mathrm{H}_{2} \mathrm{O}$ content in the MultiGAS measurements compared with the OP-FTIR measurements. There are too few measurements to study this closely, but it is possible that there is additional meteoric water in the grounded eruption cloud measured by the MultiGAS compared with the younger plume measured by the OP-FTIR using the lava as the IR source. 
The $\mathrm{SO}_{2}$ column amounts measured by the MobileDOAS system during the ring-road traverses and the in situ $\mathrm{SO}_{2}$ measurements were sometimes congruent and sometimes not (Figure 7). We identified two factors that had the largest impact on this congruence: (1) the surface concentration of gases, as measured with the in situ instrument, was not always reflecting the current state of the transporting eruption cloud. $\mathrm{SO}_{2}$ was sometimes observed by the car-mounted in situ $\mathrm{SO}_{2}$ instrument and by the hand-held personal sensors carried by local police to accumulate in valleys, particularly overnight, and particularly when winds were weak. It sometimes took hours of stronger winds to flush the older gases out of a region, meaning that the air quality was not always reflective of the location of the young eruption cloud; (2) The two kinds of measurements were most congruent when the elevated eruption cloud had smaller $\mathrm{SO}_{2}$ column amounts and the surface $\mathrm{SO}_{2}$ concentrations were strong. Weaker emissions were likely lofted to lower elevations than stronger emissions (the cloud height data is insufficiently resolved to definitively answer this). The surface measurements and the remotely detected column concentrations measured by DOAS were most likely measuring the same, coherent low-level eruption cloud. The DOAS measurements made under these conditions would have been impacted the least from atmospheric dilution.

The balloon-borne LOAC reported in [32] did not start collecting data until the instrument had reached about $1.7 \mathrm{~km}$ elevation. They found that in clean air, beneath and above the eruption cloud, the background number of particles was $5-10 \mathrm{~cm}^{-3}$, and that this was enhanced by a factor of 10-100 for a particle count of $100-500 \mathrm{~cm}^{-3}$ within the eruption cloud. The values are not directly comparable with the ground-based OPC measurements as the flow rate $(2 \mathrm{~L} / \mathrm{min}$ vs $1 \mathrm{~L} / \mathrm{min})$ and sampling interval (10 s versus $5 \mathrm{~min}$ ) are different for the LOAC and OPC, respectively. When these differences are accounted for, the converted monthly averages measured by the OPC $\left(4080-7800 \mathrm{~cm}^{-3}\right)$ are 10-80 times greater than the number of particles measured in the eruption cloud by the LOAC. The two instruments were not co-located; the OPC was installed at Möðrudalur, $72 \mathrm{~km}$ from the main eruption vent; where the background conditions and the concentration of particles within the eruption cloud could be expected to be different. An important difference between the two is that the launched instrument did not count the particles at the surface of the earth. The background dusty conditions on the surface in this area produce such high particle counts that the additional particles within the eruption cloud have a very small impact on the total number of particles. This is why we find very little difference in the particle counts by the OPC during and after the eruption.

The passing over of meteorological clouds triggered the development of a radar-detectable eruption cloud. The conditions when the eruption cloud was most frequently observed by the radar are the same conditions that allow for the pooling of gases as measured by the in situ $\mathrm{SO}_{2}$ sensor, specifically during low wind speeds and when there was a change in wind direction, and often in the morning. The timing, environmental conditions, and behavior of the radar-detectable cloud all suggest that the cloud above the eruption site detected by the radar mostly consisted of droplets, with some particles, and it was coupled in behavior with the behavior of the gas cloud. The droplet-rich nature of the eruption cloud is supported by the balloon-launch described in [32]. They found that most of the particles measured in the eruption cloud were consistent with the typology of droplets and also found evidence for increased humidity and the slowing down of the balloon due to condensation on the balloon as it traveled through the eruption cloud.

The particles within the eruption cloud likely included the minor ash produced by the eruption and dust lofted by the strong thermal gradients induced by the lava field. Particles from the eruption likely served as seeds for cloud droplets in conditions conducive to cloud formation, such as when passing rain storms induced the formation of a persistent cloud over the eruption site. The water vapor and other volcanic gases injected in the atmosphere by the eruption became detectable droplets due to condensation above the eruption site. The radar reflectivity, which is sensitive to droplets and particles, but not gases, was indirectly monitoring the gases in this gas-rich, particle-poor eruption cloud. In the future, this might allow for the development of radar algorithms suitable for initializing gas dispersion models and for plume rise speed quantification. 
From the perspective of optimizing observation/measurement frequency during future eruptions, we should continue to cultivate the use of as many different techniques as possible. In all data sets: $\mathrm{SO}_{2}$ fluxes, the ratios of other gases to $\mathrm{SO}_{2}$, and cloud heights, it is seen that the tables are populated due to the diversity of instrumentation and techniques. The environmental challenges were so great that few measurements were systematically obtained by any one single approach. In the future, we aim to augment our ground-based volcanic cloud eruption monitoring instrumentation with the use of a portable lidar system that could help with measuring the height of the eruption cloud and potentially describing the particle- and/or droplet rich nature of the eruption cloud.

Over the course of this eruption, we improved the use of several techniques. We optimized data filtering for the ScanDOAS measurements in order to remove the greatest impacts from atmospheric scattering. In the future, ScanDOAS data will be able to be processed and used much quicker than it was during this eruption, because sub-optimal wind directions will be automatically filtered from the real-time data analysis. The techniques used to calculate the fluxes from the near-vent traverses under high-emission, low-UV conditions can be automated, and we will work towards this in the future. We advanced the use of IR camera data for determining eruption cloud height, and we will attempt to automate this to retrieve cloud heights when other techniques are "blind" due to conditions such as darkness.

We will attempt to increase the frequency of gas ratio measurements. All three techniques used here, FTIR, MultiGAS, and filter pack sampling, should be attempted with as high frequency as possible. This will enable us to learn more, in the future, about the impacts of plentiful ground water, including rivers or glacier melt, affecting the eruption cloud, and differences in the emissions at the vent (important for constraining our physical models of the magmatic system) versus the emissions in the eruption cloud itself (important for constraining our dispersion models). These enhancements in future monitoring will enable us to improve our advice for people on potential mitigation actions to reduce societal harm during future eruptions.

Acknowledgments: Konradin Weber loaned a DOAS essential to the work. Bogi Brynjar Björnsson helped by making maps. Guðrún Nína Petersen helped by discussing results. Nial Peters helped collect DOAS and FTIR data. Clive Oppenheimer helped process FTIR data. Nahum Clements helped collect MultiGAS data. Porstein Jónsson and Sveinbjörn Steinpórsson helped with installing and maintaining instruments. Simon Carn helped with putting the eruption into a global context. Tamar Elias helped with contrasting the eruption with Kilauea's eruption. This work was greatly supported by the FUTUREVOLC project funded by the European Union's Seventh Program for research, technological development, and demonstration under grant agreement No 308377. BG and SA acknowledge a grant from the Swedish Research Council FORMAS. EI acknowledges NERC urgency grant NE/M021130/1. Thank you to three anonymous reviewers for their helpful suggestions and comments.

Author Contributions: Melissa A. Pfeffer contributed to all parts of the paper. Baldur Bergsson installed and maintained instruments, and collected and processed MultiGAS and FTIR data. Sara Barsotti coordinated field work, installed and maintained instruments, ran simulations, interpreted data, and wrote sections. Gerður Stefánsdóttir processed and interpreted DOAS data and collected and processed FTIR data. Bo Galle and Vladimir Conde installed ScanDOAS with IMO. Bo Galle, Santiago Arellano, and Vladimir Conde performed and processed MobileDOAS measurements. Bo Galle and Santiago Arellano analyzed DOAS data and wrote sections. Amy Donovan collected and processed DOAS and FTIR data and interpreted data. Evgenia Ilyinskaya collected and processed FTIR and filter pack data, interpreted data, and revised the paper. Mike Burton collected and processed FTIR data and interpreted data. Alessandro Aiuppa processed MultiGAS data and interpreted data. Rachel C. W. Whitty processed NicAIR II data, interpreted data, and wrote sections. Isla C. Simmons processed DOAS data, interpreted data, and wrote sections. Pórður Arason processed webcam data, interpreted data, and generated figures. Elín B. Jónasdóttir coordinated overflight data and interpreted data. Nicole S. Keller collected and processed FTIR and filter pack data. Richard F. Yeo and Hermann Arngrímsson installed and maintained instruments and collected and processed radar data. Porsteinn Jóhannsson coordinated the Icelandic Environmental Agency network and interpreted data. Mary K. Butwin processed and interpreted OPC data. Robert A. Askew collected and processed FTIR data. Stéphanie Dumont interpreted data and analyzed the time series. Stéphanie Dumont installed the OPC and interpreted data. Porgils Ingvarsson installed and maintained instruments. Alessandro La Spina collected and processed FTIR data. Helen Thomas and Fred Prata developed the NicAIR II and processed and interpreted IR camera data. Fausto Grassa analyzed direct samples. Gaetano Giudice developed the MultiGAS and interpreted data. Andri Stefánsson analyzed and interpreted filter pack samples. Frank Marzano, Mario Montopoli, and Luigi Mereu processed radar data and interpreted radar data. 
Conflicts of Interest: The authors declare no conflict of interest. The founding sponsors had no role in the design of the study; in the collection, analyses, or interpretation of data; in the writing of the manuscript, and in the decision to publish the results.

\section{References}

1. Gíslason, S.R.; Stefánsdóttir, G.; Pfeffer, M.A.; Barsotti, S.; Jóhannsson, P.; Galeczka, I.; Bali, E.; Sigmarsson, O.; Stefánsson, A.; Keller, N.S.; et al. Environmental pressure from the 2014-15 eruption of Bárðarbunga volcano, Iceland. Geochem. Perspect. Lett. 2015, 84-93. [CrossRef]

2. Bárðarbunga. Alternative Name: Veiðivötn. Available online: http://www.icelandicvolcanoes.is / ?volcano= BAR (accessed on 18 January 2018).

3. Sigmundsson, F.; Hooper, A.; Hreinsdóttir, S.; Vogfjörd, K.S.; Ófeigsson, B.G.; Heimisson, E.R.; Dumont, S.; Parks, M.; Spaans, K.; Gudmundsson, G.B.; et al. Segmented lateral dyke growth in a rifting event at Bárðarbunga volcanic system, Iceland. Nature 2014, 517, 191-195. [CrossRef] [PubMed]

4. Hartley, M.E.; Thordarson, T. The 1874-1876 volcano-tectonic episode at Askja, North Iceland: Lateral flow revisited: Askja 1874-1876 Volcano-Tectonic Episode. Geochem. Geophys. Geosyst. 2013, 14, $2286-2309$. [CrossRef]

5. Ilyinskaya, E.; Schmidt, A.; Mather, T.A.; Pope, F.D.; Witham, C.; Baxter, P.; Jóhannsson, T.; Pfeffer, M.A.; Barsotti, S.; Singh, A.; et al. Understanding the environmental impacts of large fissure eruptions: Aerosol and gas emissions from the 2014-2015 Holuhraun eruption (Iceland). Earth Planet. Sci. Lett. 2017, 472, 309-322. [CrossRef]

6. The Scientific Advisory Board of the Icelandic Civil Protection. Volcanic Activity in the Bárðarbunga system. Available online: http://en.vedur.is/media/jar/Factsheet_Bardarbunga_20150127.pdf (accessed on 10 January 2018).

7. Arnalds, O.; Dagsson-Waldhauserova, P.; Olafsson, H. The Icelandic volcanic aeolian environment: Processes and impacts-A review. Aeolian Res. 2016, 20, 176-195. [CrossRef]

8. Platt, U.; Stutz, J. Differential Optical Absorption Spectroscopy: Principles and Applications, 1st ed.; Springer: Berlin, Germany, 2008; ISBN 978-3-540-21193-8.

9. Galle, B.; Pfeffer, M.A.; Arellano, S.; Bergsson, B.; Conde, V.; Barsotti, S.; Stefánsdóttir, G.; Ingvarsson, P.; Bergsson, B.; Weber, K. Measurements of the gas emission from Holuhraun volcanic fissure eruption on Iceland, using Scanning DOAS instruments 2016. In Proceedings of the European Geosciences Union General Assembly 2016, Vienna, Austria, 17-22 April 2016; p. 13892.

10. Galle, B.; Johansson, M.; Rivera, C.; Zhang, Y.; Kihlman, M.; Kern, C.; Lehmann, T.; Platt, U.; Arellano, S.; Hidalgo, S. Network for Observation of Volcanic and Atmospheric Change (NOVAC)—A global network for volcanic gas monitoring: Network layout and instrument description. J. Geophys. Res. 2010, 115. [CrossRef]

11. HARMONIE-Numerical Weather Prediction Model. Available online: http://en.vedur.is/weather/articles/ $\mathrm{nr} / 3232$ (accessed on 10 January 2018).

12. Mori, T.; Mori, T.; Kazahaya, K.; Ohwada, M.; Hirabayashi, J.; Yoshikawa, S. Effect of UV scattering on $\mathrm{SO}_{2}$ emission rate measurements. Geophys. Res. Lett. 2006, 33. [CrossRef]

13. Johansson, M. Application of Passive DOAS for Studies of Megacity Air Pollution and Volcanic Gas Emissions. Ph.D. Thesis, Chalmers University of Technology, Gothenburg, Sweden, 2009.

14. Simmons, I.C.; Pfeffer, M.A.; Calder, E.S.; Galle, B.; Arellano, S.; Coppola, D.; Barsotti, S. Extended SO outgassing from the 2014-2015 Holuhraun lava flow field, Iceland. Bull. Volcanol. 2017, 79. [CrossRef]

15. Galle, B.; Oppenheimer, C.; Geyer, A.; McGonigle, A.J.S.; Edmonds, M.; Horrocks, L. A miniaturised ultraviolet spectrometer for remote sensing of $\mathrm{SO}_{2}$ fluxes: A new tool for volcano surveillance. J. Volcanol. Geotherm. Res. 2003, 119, 241-254. [CrossRef]

16. Johansson, M.; Galle, B.; Zhang, Y.; Rivera, C.; Chen, D.; Wyser, K. The dual-beam mini-DOAS techniqueMeasurements of volcanic gas emission, plume height and plume speed with a single instrument. Bull. Volcanol. 2009, 71, 747-751. [CrossRef]

17. Tsanev, V.I. A Collection of JScripts for Retrieval of Gas Column Amounts Using DOAS Methodology. Available online: https:/ / www.geog.cam.ac.uk/research/projects/doasretrieval/ (accessed on 10 January 2018).

18. Avoscan. Available online: https://code.google.com/archive/p/avoscan/ (accessed on 18 January 2018). 
19. Kern, C.; Deutschmann, T.; Vogel, L.; Wöhrbach, M.; Wagner, T.; Platt, U. Radiative transfer corrections for accurate spectroscopic measurements of volcanic gas emissions. Bull. Volcanol. 2010, 72, 233-247. [CrossRef]

20. La Spina, A.; Burton, M.; Harig, R.; Mure, F.; Rusch, P.; Jordan, M.; Caltabiano, T. New insights into volcanic processes at Stromboli from Cerberus, a remote-controlled open-path FTIR scanner system. J. Volcanol. Geotherm. Res. 2013, 249, 66-76. [CrossRef]

21. Burton, M.; Allard, P.; Mure, F.; La Spina, A. Magmatic gas composition reveals the source depth of slug-driven strombolian explosive activity. Science 2007, 317, 227-230. [CrossRef] [PubMed]

22. La Spina, A.; Burton, M.; Salerno, G.G. Unravelling the processes controlling gas emissions from the central and northeast craters of Mt. Etna. J. Volcanol. Geotherm. Res. 2010, 198, 368-376. [CrossRef]

23. Burton, M.; Ilyinskaya, E.; Hartley, M.; La Spina, A.; Salerno, G.G.; Bali, E.; Barsotti, S.; Bergsson, B.; Pfeffer, M.A.; Kaasalainen, H.; et al. Mantle source controls gas emissions and impact of Icelandic basaltic eruptions. Nat. Commun. 2017. submitted for publication.

24. Allard, P.; Burton, M.; Oskarsson, N.; Michel, A.; Polacci, M. Magmatic gas composition and fluxes during the 2010 Eyjafjallajökull explosive eruption: implications for degassing magma volumes and volatile sources 2011. In Proceedings of the European Geosciences Union General Assembly 2011, Vienna, Austria, 3-8 April 2011.

25. Gudmundsson, M.T.; Jónsdóttir, K.; Hooper, A.; Holohan, E.P.; Halldórsson, S.A.; Ófeigsson, B.G.; Cesca, S.; Vogfjörd, K.S.; Sigmundsson, F.; Högnadóttir, T.; et al. Gradual caldera collapse at Bárdarbunga volcano, Iceland, regulated by lateral magma outflow. Science 2016, 353, aaf8988. [CrossRef] [PubMed]

26. Aiuppa, A.; Bertagnini, A.; Métrich, N.; Moretti, R.; Di Muro, A.; Liuzzo, M.; Tamburello, G. A model of degassing for Stromboli volcano. Earth Planet. Sci. Lett. 2010, 295, 195-204. [CrossRef]

27. Aiuppa, A.; Federico, C.; Giudice, G.; Giuffrida, G.; Guida, R.; Gurrieri, S.; Liuzzo, M.; Moretti, R.; Papale, P. The 2007 eruption of Stromboli volcano: Insights from real-time measurement of the volcanic gas plume $\mathrm{CO}_{2} / \mathrm{SO}_{2}$ ratio. J. Volcanol. Geotherm. Res. 2009, 182, 221-230. [CrossRef]

28. Ilyinskaya, E.; Aiuppa, A.; Bergsson, B.; Di Napoli, R.; Fridriksson, T.; Óladóttir, A.A.; Óskarsson, F.; Grassa, F.; Pfeffer, M.; Lechner, K.; et al. Degassing regime of Hekla volcano 2012-2013. Geochim. Cosmochim. Acta 2015, 159, 80-99. [CrossRef]

29. Tamburello, G. Ratiocalc: Software for processing data from multicomponent volcanic gas analyzers. Comput. Geosci. 2015, 82, 63-67. [CrossRef]

30. Stefánsson, A.; Stefánsdóttir, G.; Keller, N.S.; Barsotti, S.; Sigurdsson, Á.; Thorláksdóttir, S.B.; Pfeffer, M.A.; Eiríksdóttir, E.S.; Jónasdóttir, E.B.; von Löwis, S.; et al. Major impact of volcanic gases on the chemical composition of precipitation in Iceland during the 2014-2015 Holuhraun eruption: impact of volcanic gas on precipitation. J. Geophys. Res. Atmos. 2017, 122, 1971-1982. [CrossRef]

31. Gauthier, P.-J.; Sigmarsson, O.; Gouhier, M.; Haddadi, B.; Moune, S. Elevated gas flux and trace metal degassing from the 2014-2015 fissure eruption at the Bárðarbunga volcanic system, Iceland: Degassing at Holuhraun. J. Geophys. Res. Solid Earth 2016, 121, 1610-1630. [CrossRef]

32. Vignelles, D.; Roberts, T.J.; Carboni, E.; Ilyinskaya, E.; Pfeffer, M.A.; Dagsson Waldhauserova, P.; Schmidt, A.; Berthet, G.; Jegou, F.; Renard, J.-B.; et al. Balloon-borne measurement of the aerosol size distribution from an Icelandic flood basalt eruption. Earth Planet. Sci. Lett. 2016, 453, 252-259. [CrossRef]

33. De Michele, M.; Raucoules, D.; Arason, P. Volcanic Plume Elevation Model and its velocity derived from Landsat 8. Remote Sens. Environ. 2016, 176, 219-224. [CrossRef]

34. Prata, A.J.; Bernardo, C. Retrieval of volcanic ash particle size, mass and optical depth from a ground-based thermal infrared camera. J. Volcanol. Geotherm. Res. 2009, 186, 91-107. [CrossRef]

35. Prata, A.J.; Bernardo, C. Retrieval of sulfur dioxide from a ground-based thermal infrared imaging camera. Atmos. Meas. Tech. 2014, 7, 2807-2828. [CrossRef]

36. Lopez, T.; Thomas, H.E.; Prata, A.J.; Amigo, A.; Fee, D.; Moriano, D. Volcanic plume characteristics determined using an infrared imaging camera. J. Volcanol. Geotherm. Res. 2015, 300, 148-166. [CrossRef]

37. Lopez, T.; Fee, D.; Prata, F.; Dehn, J. Characterization and interpretation of volcanic activity at Karymsky Volcano, Kamchatka, Russia, using observations of infrasound, volcanic emissions, and thermal imagery: Characterization of volcanic activity. Geochem. Geophys. Geosyst. 2013, 14, 5106-5127. [CrossRef]

38. Whitty, R.C.W. The Use of an Infrared Camera to Analyse a Volcanic Eruption Extraordinarily Rich in $\mathrm{SO}_{2}$ and $\mathrm{H}_{2} \mathrm{O}$. Master's Thesis, The University of Edinburgh, Edinburgh, 2016.

39. Scollo, S.; Prestifilippo, M.; Pecora, E.; Corradini, S.; Merucci, L.; Spata, G.; Coltelli, M. Eruption column height estimation of the 2011-2013 Etna lava fountains. Ann. Geophys. 2014. [CrossRef] 
40. Arason, P.; Petersen, G.N.; Bjornsson, H. Observations of the altitude of the volcanic plume during the eruption of Eyjafjallajökull, April-May 2010. Earth Syst. Sci. Data 2011, 3, 9-17. [CrossRef]

41. Björnsson, H.; Petersen, G.N.; Arason, P.; Jónasdóttir, E.B.; Ólafsson, H.; Pfeffer, M.A.; Barsotti, S.; Palmason, B.; von Löwis, S.; Dürig, T. Interaction Between the Eruption at Holuhraun and the Ambient Atmosphere 2015. In Proceedings of the European Geosciences Union General Assembly 2015, Vienna, Austria, 12-17 April 2015.

42. Marzano, F.S.; Lamantea, M.; Montopoli, M.; Di Fabio, S.; Picciotti, E. The Eyjafjöll explosive volcanic eruption from a microwave weather radar perspective. Atmos. Chem. Phys. 2011, 11, 9503-9518. [CrossRef]

43. Marzano, F.S.; Barbieri, S.; Vulpiani, G.; Rose, W.I. Volcanic ash cloud retrieval by ground-based microwave weather radar. IEEE Trans. Geosci. Remote Sens. 2006, 44, 3235-3246. [CrossRef]

44. Mereu, L.; Marzano, F.S.; Barsotti, S.; Montopoli, M.; Yeo, R.; Arngrimsson, H.; Björnsson, H.; Bonadonna, C. Ground-based microwave weather radar observations and retrievals during the 2014 Holuhraun eruption (Bárðarbunga, Iceland). In Proceedings of the European Geosciences Union General Assembly 2015, Vienna, Austria, 12-17 April 2015.

45. Arason, P.; Björnsson, H.; Petersen, G.N.; Jónasdóttir, E.B.; Oddsson, B. Plume height during the 2014-2015 Holuhraun volcanic eruption. In Proceedings of the European Geosciences Union General Assembly 2015, Vienna, Austria, 12-17 April 2015.

46. Coppola, D.; Ripepe, M.; Laiolo, M.; Cigolini, C. Modelling satellite-derived magma discharge to explain caldera collapse. Geology 2017, 45, 523-526. [CrossRef]

47. Bali, E.; Hartley, M.; Halldórsson, S.A.; Gudfinnsson, G.H.; Jakobsson, S. Melt inclusion constraints on volatile systematics and degassing history of the 2014-2015 Holuhraun eruption, Iceland. Contrib. Mineral. Petrol. 2017. submitted for publication. [CrossRef]

48. Pedersen, G.B.M.; Höskuldsson, Á.; Dürig, T.; Thordarson, T.; Jónsdóttir, I.; Riishuus, M.S.; Óskarsson, B.V.; Dumont, S.; Magnusson, E.; Gudmundsson, M.T.; et al. Lava field evolution and emplacement dynamics of the 2014-2015 basaltic fissure eruption at Holuhraun, Iceland. J. Volcanol. Geotherm. Res. 2017, 340, 155-169. [CrossRef]

49. Schmidt, A.; Leadbetter, S.; Theys, N.; Carboni, E.; Witham, C.S.; Stevenson, J.A.; Birch, C.E.; Thordarson, T.; Turnock, S.; Barsotti, S.; et al. Satellite detection, long-range transport, and air quality impacts of volcanic sulfur dioxide from the 2014-2015 flood lava eruption at Bárðarbunga (Iceland): SO from 2014 to 2015 eruption at Bárðarbunga. J. Geophys. Res. Atmos. 2015, 120, 9739-9757. [CrossRef]

50. Carn, S.A. Global Sulfur Dioxide Monitoring Home Page. Available online: https://so2.gsfc.nasa.gov/ (accessed on 14 September 2017).

51. Sutton, A.J.; Elias, T.; Gerlach, T.M.; Stokes, J.B. Implications for eruptive processes as indicated by sulfur dioxide emissions from Kilauea Volcano, Hawai'i, 1979-1997. J. Volcanol. Geotherm. Res. 2001, 108, 283-302. [CrossRef]

52. Hellsing, V.Ú.L.; Ragnarsdóttir, A.S.; Jónsson, K.; Keller, N.S.; Jóhannsson, P.; Guðmundsson, J.; Snorrason, A.; Pórsson, J. National Inventory Report: Emissions of Greenhouse Gases in Iceland from 1990 to 2015; The Environment Agency of Iceland: Reykjavík, Iceland, 2017.

53. Aiuppa, A.; Baker, D.R.; Webster, J.D. Halogens in volcanic systems. Chem. Geol. 2009, 263, 1-18. [CrossRef]

54. Aiuppa, A.; Bellomo, S.; D'Alessandro, W.; Federico, C.; Ferm, M.; Valenza, M. Volcanic plume monitoring at Mount Etna by diffusive (passive) sampling. J. Geophys. Res. Atmos. 2004, 109. [CrossRef]

55. Butz, A.; Dinger, A.S.; Bobrowski, N.; Kostinek, J.; Fieber, L.; Fischerkeller, C.; Giuffrida, G.B.; Hase, F.; Klappenbach, F.; Kuhn, J.; et al. Remote sensing of volcanic $\mathrm{CO}_{2}, \mathrm{HF}, \mathrm{HCl}, \mathrm{SO}_{2}$, and $\mathrm{BrO}$ in the downwind plume of Mt. Etna. Atmos. Meas. Tech. 2017, 10, 1-14. [CrossRef]

56. Granieri, D.; Salerno, G.; Liuzzo, M.; La Spina, A.; Giuffrida, G.; Caltabiano, T.; Giudice, G.; Gutierrez, E.; Montalvo, F.; Burton, M.R.; et al. Emission of gas and atmospheric dispersion of $\mathrm{SO}_{2}$ during the December 2013 eruption at San Miguel volcano (El Salvador, Central America): $\mathrm{SO}_{2}$ emission at San Miguel volcano. Geophys. Res. Lett. 2015, 42, 5847-5854. [CrossRef]

57. Martin, R.S.; Sawyer, G.M.; Spampinato, L.; Salerno, G.G.; Ramirez, C.; Ilyinskaya, E.; Witt, M.L.I.; Mather, T.A.; Watson, I.M.; Phillips, J.C.; et al. A total volatile inventory for Masaya Volcano, Nicaragua. J. Geophys. Res. 2010, 115. [CrossRef]

58. Oppenheimer, C.; Scaillet, B.; Martin, R.S. Sulfur degassing from volcanoes: Source conditions, surveillance, plume chemistry and earth system impacts. Rev. Mineral. Geochem. 2011, 73, 363-421. [CrossRef] 
59. Pennisi, M.; Le Cloarec, M.-F. Variations of Cl, F, and S in Mount Etna's plume, Italy, between 1992 and 1995. J. Geophys. Res. Solid Earth 1998, 103, 5061-5066. [CrossRef]

60. Sawyer, G.M.; Carn, S.A.; Tsanev, V.I.; Oppenheimer, C.; Burton, M. Investigation into magma degassing at Nyiragongo volcano, Democratic Republic of the Congo: Magma degassing at Nyiragongo volcano. Geochem. Geophys. Geosystems 2008, 9. [CrossRef]

61. Spampinato, L.; Salerno, G.G.; Martin, R.S.; Sawyer, G.M.; Oppenheimer, C.; Ilyinskaya, E.; Ramirez, C. Thermal and geochemical signature of Poas volcano, Costa Rica. Rev. Geol. Am. Cent. 2010, 43, 171-189.

62. Symonds, R.B.; Rose, W.I.; Bluth, G.J.S.; Gerlach, T.M. Volcanic gas studies: Methods, results and applications. Rev. Mineral. Geochem. 1994, 30, 1-66.

(C) 2018 by the authors. Licensee MDPI, Basel, Switzerland. This article is an open access article distributed under the terms and conditions of the Creative Commons Attribution (CC BY) license (http:/ / creativecommons.org/licenses/by/4.0/). 